2011-08-01

Morphodynamic characteristics and classification of beaches in England and Wales

\author{
Scott, Tim
}

http://hdl.handle.net/10026.1/1053

10.1016/j.margeo.2011.04.004

MARINE GEOLOGY

Elsevier BV

All content in PEARL is protected by copyright law. Author manuscripts are made available in accordance with publisher policies. Please cite only the published version using the details provided on the item record or document. In the absence of an open licence (e.g. Creative Commons), permissions for further reuse of content should be sought from the publisher or author. 


\title{
Morphodynamic characteristics and classification of beaches in England and Wales
}

\author{
Tim Scott*, Gerhard Masselink, Paul Russell \\ School of Marine Science and Engineering, University of Plymouth, Drake Circus, Plymouth, PL4 8AA, UK
}

\section{A R T I C L E I N F O}

Article history:

Received 12 October 2010

Received in revised form 10 April 2011

Accepted 24 April 2011

Available online 11 May 2011

Communicated by: J.T. Wells

\section{Keywords:}

beach morphodynamics

beach morphology

beach classification

hierarchical cluster analysis

multi-dimensional scaling

macrotidal

rip currents

wave power

risk assessment

beach hazard

\begin{abstract}
A B S T R A C T
The use of beach classification models has become widespread in literature in recent years. Beach classification models that recognise distinct modal beach states in response to environmental conditions are most widely used. These models were developed largely in high-energy, micro- to meso-tidal sandy environments and subsequent attention has focussed on extending their use into other beach environments. Here, the applicability of these traditional beach classification models to the highly diverse coastline of England and Wales was assessed through collection of detailed morphodynamic characteristics of 92 beaches, yielding a comprehensive multi-variate data set containing morphological, sedimentological and hydrodynamic information. The complex and diverse study region incorporates beach morphology covering the full spectrum from reflective to dissipative, and non-barred to multi-barred. Cluster analysis supplemented by MDS ordination resulted in the identification of 9 distinct beach types. Traditional morphodynamic indices $\Omega$ and RTR were found to be effective in discriminating between beach groups providing some support for the beach state models derived using information from Australian beaches. It was found that absolute wave energy (wave power) is important as well in controlling beach type. For intermediate beaches a wave energy flux $P\left(\propto H^{2} T\right)$ value of $3 \mathrm{~kW} \mathrm{~m}^{-1}$ was found to differentiate between beaches with $\left(P>3 \mathrm{~kW} \mathrm{~m}^{-1}\right)$ and without $\left(P<3 \mathrm{~kW} \mathrm{~m}^{-1}\right)$ threedimensional bar/rip morphology, a key component controlling recreational beach hazard levels. Observations presented here inform a beach classification model to be used as the basis for a national beach risk assessment programme. Beach classification models based on environmental parameters are, by necessity, simplifications and should be used as tools for understanding morphodynamic systems, rather than beach type prediction.
\end{abstract}

(C) 2011 Elsevier B.V. All rights reserved.

\section{Introduction}

Beach morphology varies in time with changing hydrodynamic forcing (waves and tides), while the modal beach morphology changes spatially in response to the geographical variability in environmental conditions (waves, tides, sediments, geology, etc.). This notion has resulted in the formulation of beach classification models that recognise the occurrence of distinct beach morphologies, or beach states/types, and link these to parameterisations of the key environmental conditions, namely wave climate, tidal regime and beach sediment characteristics. The most widely used of such models is the so-called Australian beach model, originally devised separately and independently by Chappell and Eliot (1979), Short (1979a) and Wright et al. (1979), and subsequently refined by Wright and Short (1984) and Wright et al. (1987).

The Australian beach model was based on the study of sandy beaches along the high-wave energy and microtidal (mean spring tidal range MSR $<2 \mathrm{~m}$ ) coastline of New South Wales, Australia. The key parameter in this model is the dimensionless fall velocity $\Omega$ given by $H / w_{s} T$, where $H$ is the (breaking) wave height, $w_{s}$ is the (high tide) sediment fall velocity and $T$ is the (peak) wave period (Gourlay,

\footnotetext{
* Corresponding author. Tel.: + 441752584719.

E-mail address: timothy.scott@plymouth.ac.uk (T. Scott).
}

1968). Different classifications have been developed for other beach environments, for example the model of Hegge et al. (1996) developed for the microtidal and sheltered coastline of southwestern Western Australia, Short's (1991) model based on the macrotidal ( $4 \mathrm{~m}<$ MSR $<8 \mathrm{~m}$ ) beaches of central Queensland, Australia, and the classification of Jennings and Shulmeister (2002) based on a study of New Zealand gravel beaches. Masselink and Short (1993) used the Australian beach model as a starting point and extended it to account for the relative importance of tides and waves parameterised by the relative tide range RTR given by MSR/H, where MSR is the mean spring tide range. Based on the analysis of all 10,685 beach systems present in Australia, Short (2006) added a further two geologically-controlled and four low energy beach types to the combined models of Wright and Short (1984) and Masselink and Short (1993).

Beach classifications are useful in providing a conceptual framework within which beach and surf zone environments can be studied and understood, and the wide use of beach models for this purpose is demonstrated by the large amount of citations for beach classification papers (487 for Wright and Short, 1984; 70 for Short, 1991; 177 for Masselink and Short, 1993; 44 for Hegge et al., 1996; 27 for Jennings and Shulmeister, 2002; all based on Google Scholar checked on 6 June 2010). Because beach sedimentology and hydrodynamic processes are strongly correlated to beach fauna Defeo and McLachlan, (2005), beach classification models are also useful for providing the physical 
framework for beach ecologists. For example, both species' abundance and diversity are strongly linked to beach state and can be parameterised by similar parameters on which beach classification models are based (Rodil and Lastra, 2004). Finally, due to the link between beach morphology and surf hazards to bathers, beach classification models have also been used as the basis for beach risk assessment (Short, 1993,1999), with particular emphasis on the role of rip currents (Short and Hogan, 1994; Scott et al., 2009).

Beach classification models are generally based on a large amount of temporal and/or spatial observations, and are most applicable to the environment whence the observational data were collected. Application of a model outside the region for which it was developed can lead to general support (Sénéchal et al., 2009), modification (Costas et al., 2005) or outright rejection (Jackson et al., 2005) of the model. It is important to recognise that there is a fundamental difference between validation studies based on temporal data and those based on spatial data. In the former case, time series of beach state are used to investigate the morphological variability and beach state transitions on a single beach as a result of varying forcing conditions and often suggest that beach state is strongly reliant on the previous state (Costas et al., 2005; Jiménez et al., 2008; OrtegaSánchez et al., 2008; Sénéchal et al., 2009). In the latter case, the modal beach state on a large number of beaches is linked to forcing factors and such studies tend to highlight the importance of factors specific to the study area, such as geology (Jackson et al., 2005) and wave height variability (Gómez-Pujol et al., 2007).

Two critical factors in the formulation and/or application of beach classification models are the objective characterisation of the beach state and correct parameterisation of the environmental factors (and whether the selected parameters are indeed appropriate; cf., Anthony, 1998). Early beach typologies were based on field sketches that captured the three-dimensionality of the morphology, supplemented with two-dimensional beach surveys (Chappell and Eliot, 1979; Short, 1979b). More sophisticated methods for characterising the beach morphology include three-dimensional beach surveys involving GPS (e.g., Sénéchal et al., 2009) and ARGUS video-monitoring (e.g., Ranasinghe et al., 2004). However, despite the sophistication of the methodology, in most studies the actual identification of the beach state is a manual process and therefore highly subjective. To avoid this problem, both Hegge et al. (1996) and Jennings and Shulmeister (2002) have deployed multivariate analytical techniques (cluster analysis and discriminant analysis, respectively) to help them objectively identify and classify the dominant beach types.

The problem with correctly parameterising the forcing conditions, in particular the inshore wave height and period, is potentially more significant. In temporal studies, the inshore wave field can be characterised using deep-water wave data, especially if a wave buoy is located immediately off the beach (e.g., Ortega-Sánchez et al., 2008; Sénéchal et al., 2009). However, in spatial studies, reliable inshore wave data are rarely available for all beaches in the data set and need to be estimated. Unless a numerical model is deployed to transform deep water wave conditions to the inshore for each of the beaches, breaker conditions are unlikely to be estimated correctly. As an example, in the study of Jackson et al. (2005), the average breaker conditions on 25 beaches were estimated by applying a simple shoaling equation to deep water wave data, without taking account of sheltering provided by headlands or consideration of the shoreline orientation relative to the dominant wave direction. As a result, the breaker conditions were considerably overestimated, with mean wave heights along the relatively low wave energy northeast coast of Ireland of c. $1.5 \mathrm{~m}$. This, together with the use of the mean instead of the peak wave period, led to all but one of the north Irish beaches predicted to be ultra-dissipative, which as the study states, represents a poor characterisation of the actual beach morphology.

Jackson et al. (2005) highlight the role of site context within their dataset in constraining beach morphological change. They suggest that the complexity of beach morphological systems means that in many beach environments the morphological realisation of these dynamic forcing conditions (waves and currents) can, to varying extents, be constrained by the geological site context. On both a temporal and spatial scale, the geological framework within which a beach exists can impose important boundary conditions to the evolution of beach morphological state, affecting nearshore wave transformations, and sediment abundance and accommodation space (Jackson and Cooper, 2009; Short and Jackson, in press). Short and Jackson (in press) concede that much of the development of beach classification models and thinking on beach morphodynamics is dominated by consideration of unconstrained beach environments emphasising the importance of considering the role of geological site context when assessing the effectiveness of morphodynamic indices in the application of beach classification models outside of their region of development.

The aim of the present paper is to provide an overview of the spatial variability in beach morphology along the highly diverse coastline of England and Wales and synthesise the observations in a beach classification model that can be used as the basis for a national beach risk assessment programme. Previous work by Scott et al. (2009) identified the importance of rip currents and associated morphology in controlling recreational beach hazards in England and Wales. It was therefore important that a resulting classification model incorporated the presence/absence of rip morphology as well as representing the full spectrum of beach types and hazards likely to be encountered by bathers and therefore be of interest to beach safety managers. To this end, the database in this study comprises a broad cross-section of 92 beaches and, for each of these, beach type was classified objectively using cluster analysis based on morphology, sedimentology and hydrodynamics, with inshore wave conditions estimated using a combination of observational wave data and numerical modelling. In recognition of the site-specificity of coastal geomorphology, the classification approach adopted here is datadriven, but at the same time directed towards a purpose (i.e., national beach risk assessment programme). The outline of this paper is as follows. Section 2 presents an extensive description of the coastline of England and Wales, the prevailing environmental conditions and the data set used in this study. Section 3 describes the dominant beach morphologies and their grouping, while Section 4 explores the relation between beach type and morphodynamic indices. Section 5 introduces and discusses the final classification model and conclusions are presented in Section 6.

\section{Study area and dataset}

\subsection{Boundary conditions along the coastline of England and Wales}

The coast of England and Wales is one of the most diverse coastlines in the world and a large variety of coastal landforms are represented, including dunes, sand and gravel beaches, barriers and spits, various types of estuaries, tidal flats and salt marshes, rapidly eroding soft-rock cliffs and resistant hard-rock cliffs with shore platforms (e.g., Steers, 1946; May and Hansom, 2003). Accordingly, the setting of the many beaches also varies widely and the beach morphology covers the full spectrum from reflective to dissipative, and non-barred to multi-barred. The large variety in coastal settings and beach systems is mainly attributed to the along-coast variability in static and dynamic environmental factors, or boundary conditions, and the most important of these for beach morphology are geology, sediments and external forcing (wind, waves, storms and tides). The geographic variability in these boundary conditions is summarised in Fig. 1.

Long-term coastal evolution is largely driven by changes in (relative) sea level. At the end of the glacial maximum, around 18,000 years ago, global sea level started to rise rapidly from c. $120 \mathrm{~m}$ 

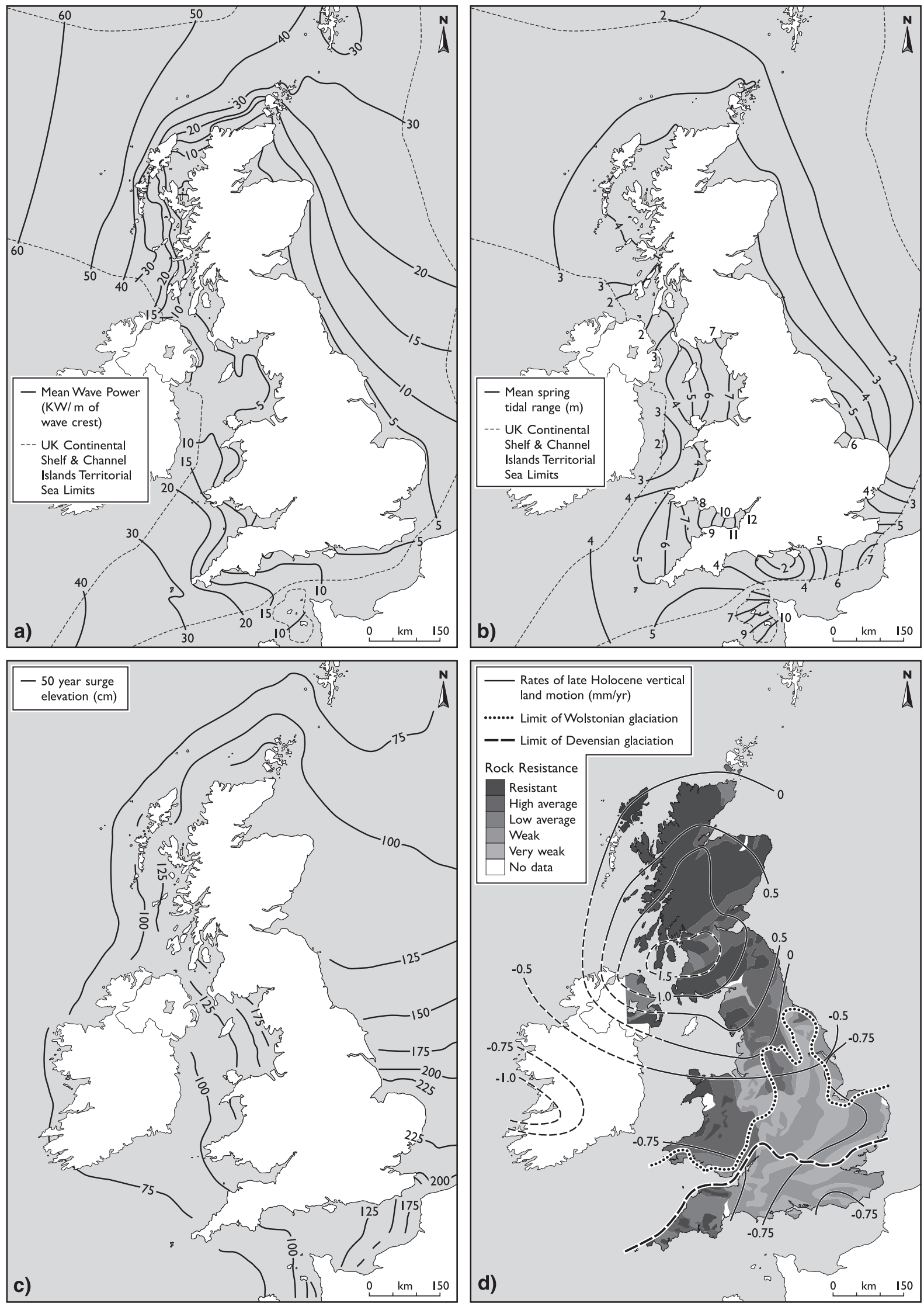

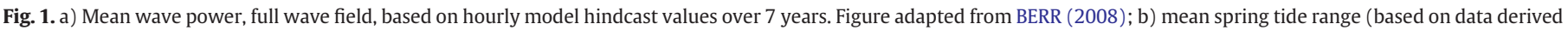

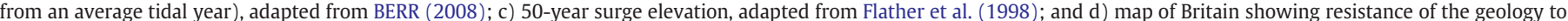
denudation (Clayton and Shamoon, 1998) and rates of late Holocene vertical land motion (Gehrels, 2010). 
below present sea level, attaining its present level around 4000 years ago (Fairbanks, 1989). The effect of this sea-level rise on the coastline of England and Wales must be considered in combination with the changes in the vertical land level associated with glacio-isostatic effects (Fig. 1d), in particular isostatic rebound of the formerly glaciated areas in the north, and collapse of the forebulge of areas near the ice margin in the south (Gehrels, 2010). These relative sea level changes have significant implications for sinking east coast regions fringing the shallow North Sea. This coastline is very young and is likely to be in disequilibrium, being significantly affected by relaxation time effects.

The large-scale solid geology, characterised by a decrease in age from west to east, forms the template of the overall coastal topography and the outline of the coast. The geology exerts its control on coastal morphology mainly through the resistance of the rocks to denudation (Fig. 1d) (Clayton and Shamoon, 1998) and this provides the explanation for the contrast between the high-relief, mainly rocky coast of west England and Wales and the low-relief, mainly unconsolidated coasts of east England. Accordingly, the west and north-east coasts of England and Wales are characterised by embayed beaches, while long sweeping beaches are more common along the south and east coasts of England.

In addition to the solid geology, the drift geology is also important, and is mainly a legacy of the most recent and penultimate glaciations, the Devensian and Wolstonian, respectively (Fig. 1d). During deglaciation, large quantities of glacial and paraglacial sediments, comprising the full spectrum of sediment sizes from mud to boulders, were left by the retreating glaciers. The coarser material, most of which was deposited on what is now the continental shelf, has been transported onshore during the post-glacial transgression and has been incorporated in dunes, beaches, barriers and estuaries (Defra, 2002; Orford et al., 2002). This sediment source is now mostly depleted and offshore sediment supply to the coast by natural processes is very limited. However, most of the material that was deposited on what is now land is still present and represents an important sediment source to the nearshore system through soft-cliff erosion, particularly along the east coast of England (Bray and Hooke, 1997). The finer fractions of these eroded glacially-derived sediments (mud and silt) are being deposited on salt marshes and tidal flats in estuarine environments, or are transported to the southern North Sea by tidal currents (Dyer and Moffat, 1998). The coarser fractions (sand and gravel) enter the littoral system and are distributed along the coast. The geology along the south coast of England is of mediumresistance and the erosion of these cliffs also provides a significant source of sediment to the nearshore system (Bray and Hooke, 1997). The paraglacial history and extensive cliff erosion provide the key explanation for the relative large proportion of gravel and mixed sand/gravel beach and barrier systems in England and Wales (c. 25\%).

The tidal range varies considerably along the coast of England and Wales due to the presence of several amphidromic systems and the interactions between the tidal motion and the coastal topography (Fig. 1b). The largest tides occur in the Bristol Channel due to the funnelling effect of the coastal topography and the smallest tides are experienced in the lee of the Isle of Wight in proximity to the degenerate amphidromic point near Bournemouth. For the majority of the coast, the amplitude of the M2 tidal component exceeds $1.5 \mathrm{~m}$ and the mean spring tide range along the open coast (excluding estuaries) is $5.5 \mathrm{~m}$.

Inshore wave conditions also vary significantly along the coast of England and Wales (Fig. 1a). The most energetic wave conditions are experienced in the southwest, where the $50 \%$ exceedence significant wave height $\left(H_{s, 50 \%}\right)$ is larger than $1 \mathrm{~m}$ and the wave climate is a mixture of Atlantic swell and locally-generated wind waves. The lowest wave conditions prevail along the northwest and east coasts of England, where waves are predominantly wind waves and $H_{s, 50 \%}$ is generally less than $0.5 \mathrm{~m}$. The influence of exposure to the Atlantic
Ocean along the southwest coast of England and to a lesser extent in the Irish Sea increases the contribution of long-period, swell waves to the wave spectrum (Fig. 2). The complexities of coastal orientation and exposure around the coasts of England and Wales lead to a dynamic balance of clearly defined high/low wave energy and wind/ swell wave components that is often characterised by a bimodal wave energy spectrum with multiple directional sources in many regions (Bradbury et al., 2004) (Fig. 2). Mean seasonal variation in wave climate is significant in many coastal regions with strong summerwinter wave energy variations. For example, wave buoy data from the Atlantic southwest coast of England shows 10\% exceedence significant wave heights ranging from $2 \mathrm{~m}$ to $5 \mathrm{~m}$ from summer to winter, respectively (Scott, 2009). Further analysis of storm wave characteristics along the Atlantic west coast illustrates the extreme high wave conditions experienced in west coast regions. On average, $17.4 \mathrm{storm}$ events (peak $H_{s}>4 \mathrm{~m}$ ) and 5 severe storm events (peak $H_{s}>6 \mathrm{~m}$ ) occur annually (Scott, 2009).

In addition to tide range and wave conditions, extreme water level conditions during storms in the form of storm surge are also important forcing factors for coastal morphology. The distribution of extreme surge height around the UK coast is plotted in Fig. 1c and indicates that the areas particularly prone to storm surge are the east coast of England with a 1:50 year storm surge height of 1.5-2.5 m, and the northwest coast of England and the Bristol Channel with a 1:50 year storm surge height of $\sim 1.5 \mathrm{~m}$ (Flather et al., 1998).

\subsection{Study sites}

Based on the geographical distribution in the boundary conditions outlined in the previous section, a comprehensive campaign of data collation and collection was undertaken to generate a representative and robust dataset of morphometric and hydrodynamic attributes for a large number of beaches. While the collection of a fully representative and unbiased dataset is always desirable, there are inherent physical and financial limitations in conducting random sampling strategies on this scale. Due to these limitations representative site selection was based on current understanding of UK beach morphodynamics and some far-field site selection was influenced by third party data availability. Data were collected from 92 beach sites within England and Wales (Fig. 3). These sites were broken down into 5 main regions: (A) Irish Sea and (B) Liverpool Bay, the (C) Atlantic southwest, (D) Lyme Bay, the (E) Channel Coast and the (F) East Coast. These different regions represent a broad cross section of beach types and environmental settings observed in the UK, possessing a marked difference in wave climate, sediment type and abundance, geological history and tidal range.

Wave climate statistics for 2007, from the MetOffice UK Waters Wave Model, are represented in Fig. 2 demonstrating the significant wave climate variations across the study regions. The Atlantic southwest represents a macro- to megatidal (MSR $>8 \mathrm{~m}$ ) high-energy open-coast dominated by high hard rock cliffs and embayed sandy beaches. A reduction in Atlantic exposure along the macrotidal Irish Sea and micro- to macrotidal Channel coasts (including Lyme Bay) resulting in a more complicated bimodal wave frequency spectrum as attenuated Atlantic swell waves and local wind seas combine. A range of backshore geomorphology (barriers, estuaries, soft and hard rock cliffs and open coasts), sediment type and abundance occurs throughout these mixed wave regions. The East Coast, although dominated by steep wind seas, also experiences a mixed sea/swell wave climate with the longer period, swell wave input coming from the northern North Sea and Arctic Ocean. Tide range varies from meso- $(2 \mathrm{~m}<\mathrm{MSR}<4 \mathrm{~m}$ ) to macrotidal moving northward along the largely uninterrupted open coastline that is characterised by low softrock rapidly eroding cliffs punctuated by two large estuarine systems, the Humber and the Wash. Finally, study sites in Liverpool Bay 


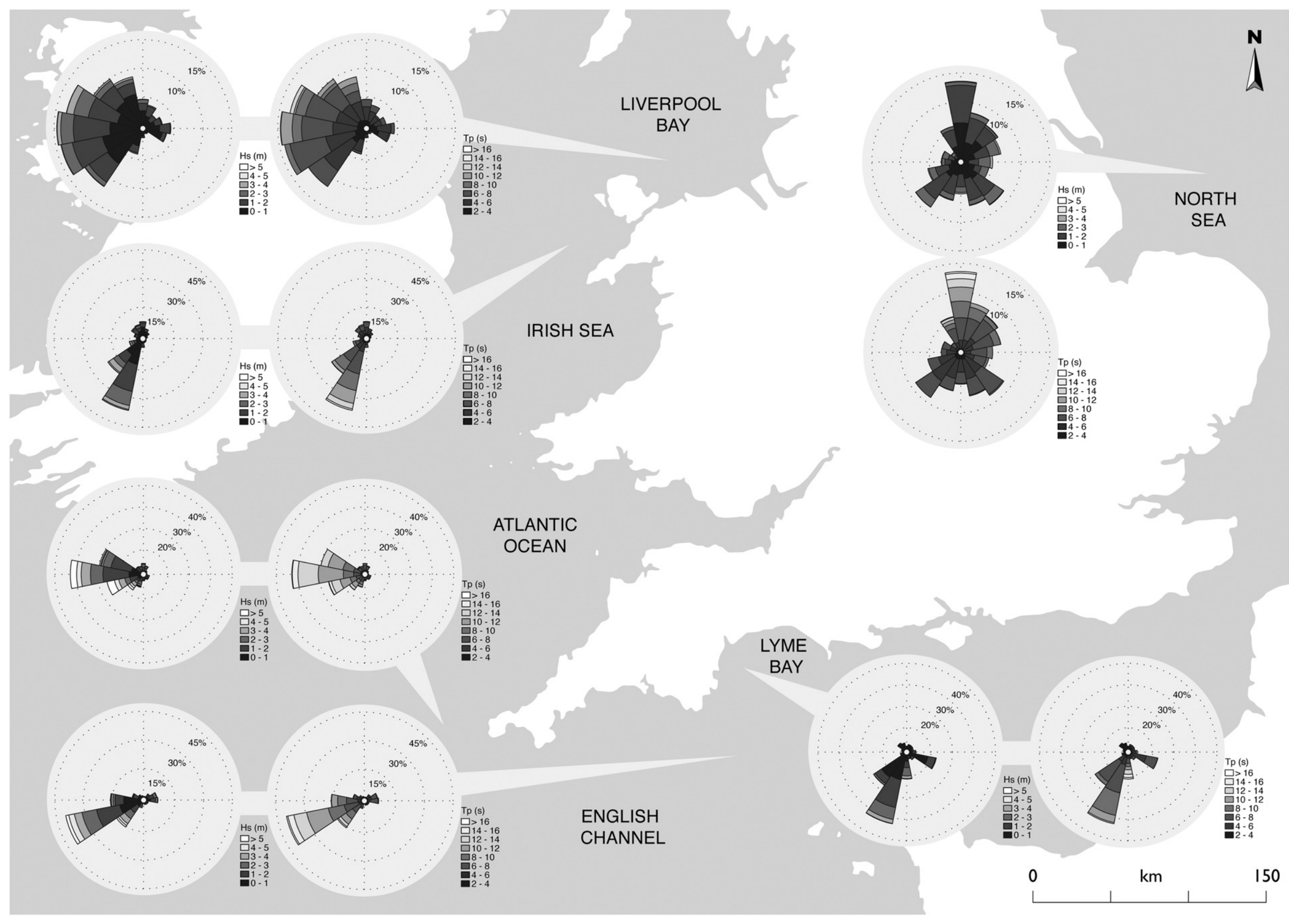

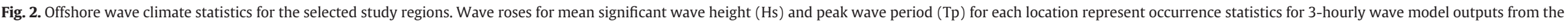
MetOffice UK Waters Wave Model during 2007. Wave direction corresponds to peak wave period. 


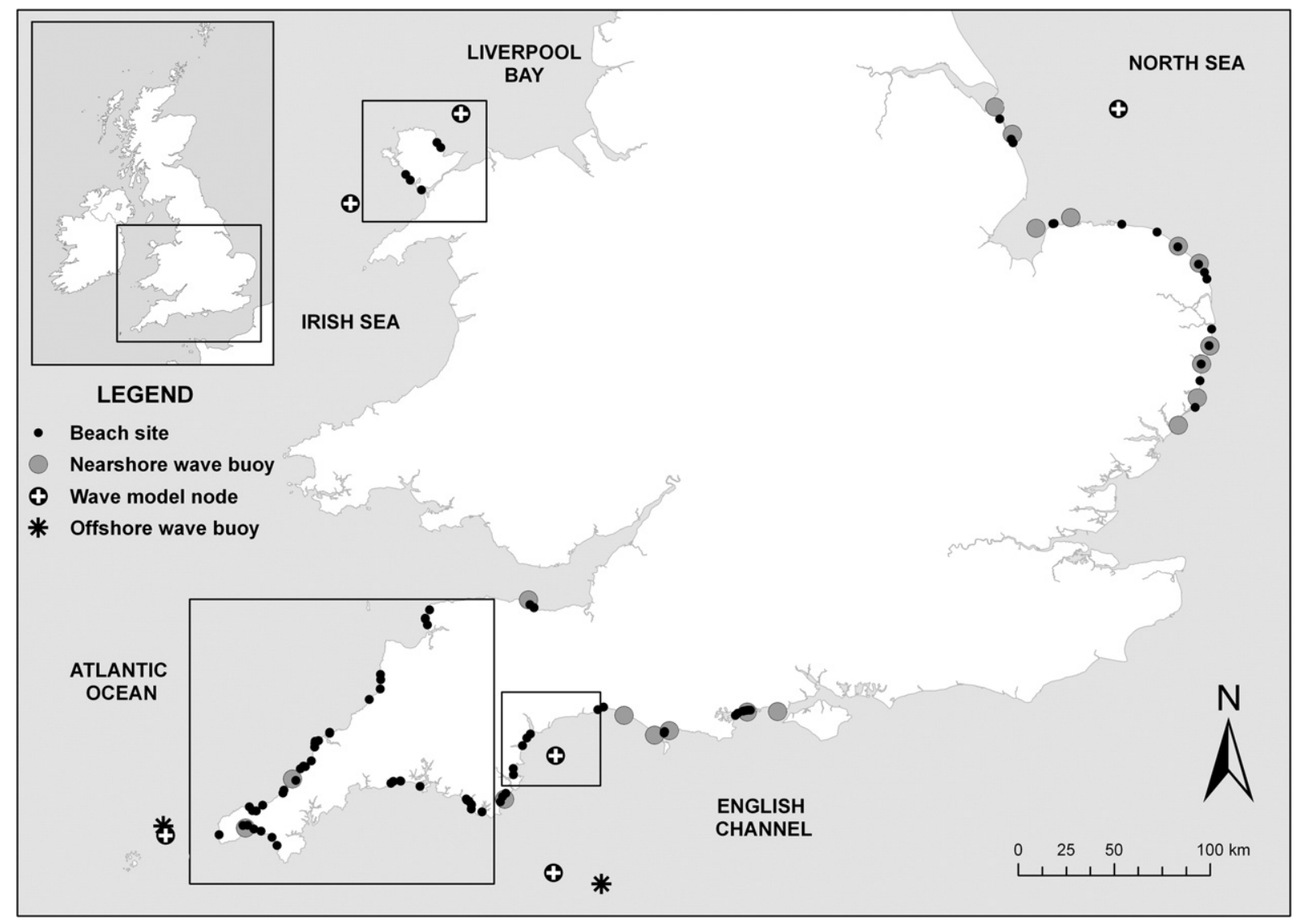

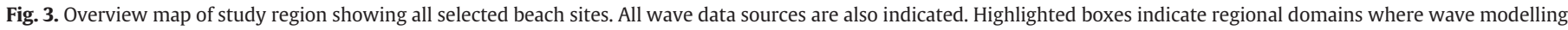
was performed.

represent a macrotidal, shallow, sediment-rich, fetch-limited wind wave environment.

\subsection{Data collection and assimilation}

Within each of the study regions indicated in Fig. 3 a campaign of data collection was undertaken between late September and early December 2007. Morphological, sedimentological and hydrodynamic datasets were collected for each beach, as well as information on the local environmental setting and extended morphological characteristics. For regions where primary data (beach surveys and sediment samples) could not be collected, reliable third party sources were utilised (Environment Agency, Channel Coastal Observatory, University of Wales Bangor). The data collection programme was designed to be as temporally synchronous as possible to minimise inter-site temporal variations in collected data due to changing forcing conditions. Using the methodology outlined in Fig. 4, a large number of morphological, sedimentological and hydrodynamic parameters were then derived and the resulting data matrix was used as the basis for further analysis.

The beach profile was used to extract morphometric indices, such as beach width and gradient (for different segments: upper, mid and lower intertidal), and beach sediment samples taken from around the high and low tide marks were used to determine sediment size (from sieving) and fall velocity (using settling tube). An assessment of the bar morphology is crucial to the quality and usefulness of this dataset due to the important role of bar morphology in controlling beach type (Wright and Short, 1984; Lippmann and Holman, 1990). For most beaches in the data set, the cross-shore profile provided an adequate measure of the beach morphology, but a significant number of the beaches displayed pronounced three-dimensional bar morphology. For these beaches, remote imagery, acquired through oblique and aerial photographs, was used to evaluate the bar characteristics. A simple visual assessment of bar characteristics illustrated in Fig. 5 was used for this purpose. Bars were classified in terms of type and shape, whereby bar type is defined by the presence of bars and their number, and bar shape describes the threedimensional nature of the bar systems. Rhythmic bar systems that possess highly three-dimensional characteristics are commonly associated with rip current circulation and intermediate morphodynamic regimes (crescentic, rhythmic and transverse bar systems).

For each beach, a number of hydrodynamic parameters were determined (MSR, $H_{s, 10 \%}$ and $H_{s, 50 \%} T_{p}$ and $T_{m}$ ). MSR was taken from the UK Hydrographic Office tide tables (Admiralty, 2007), but if a beach was not in the immediate vicinity of a Primary or Secondary Port, it was obtained using linear interpolation. Wave height is a critical parameter for computing both $\Omega$ and RTR, and due to its importance cannot simply be estimated on the basis of the offshore wave conditions. The method of calculation of wave period is significant when computing the dimensionless fall velocity. For this study, the mean wave period was used as this was a more reliably estimated statistic across both measured and modelled inshore waves. A variety of methods were deployed to obtain the appropriate inshore wave conditions for each of the beaches in the database depending on the availability of offshore and inshore wave data.

The sensitivity of traditional morphodynamic indices to the derivation of wave parameters is well established (cf., Anthony, 1998; Masselink and Pattiaratchi, 2000). Therefore, the availability of inshore wave buoy data was a priority when selecting beach sites, but to enable the sampling of a broad range of beach environments, some sites were selected that were not in the proximity of measured wave data. For beaches in all regions except the Irish Sea and Liverpool Bay, some or all of the selected sites were sufficiently close to inshore wave 


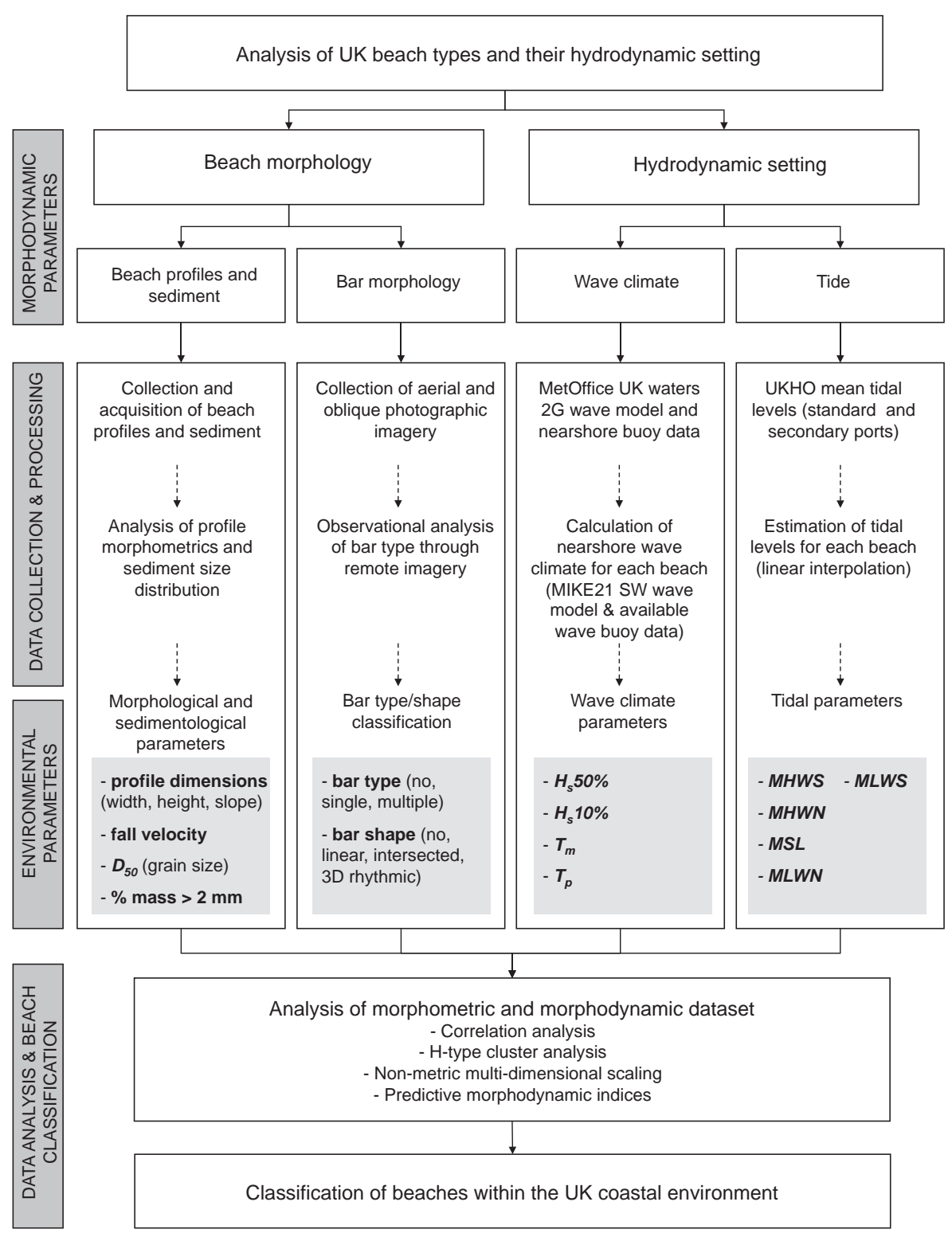

Fig. 4. Flow diagram of research methodology of the beach classification study.

buoys. Inshore wave conditions were extracted from directional wave buoy data from buoys deployed in relatively shallow water $(8-10 \mathrm{~m})$. The wave direction was accounted for by only considering shoreward propagating waves. For beaches where measured wave data was not available, inshore wave conditions were obtained through the use of a numerical model (MIKE21) forced by hindcast offshore wave model data from the MetOffice UK Waters Wave Model (Scott, 2009).In all cases, representative annual wave statistics were calculated using data from 2007. Where possible, model results were validated using inshore wave data. Although the resulting parameterisation of the inshore wave conditions is not perfect, it is far superior to simple estimation (Masselink and Short, 1993), or using linear shoaling of the offshore wave conditions without any consideration of the wave direction and wave refraction processes (Jackson et al., 2005).

\subsection{Overview of data}

Fig. 6 illustrates the round coast variation in wave height, wave period and MSR with each of the six discrete regions A-F representing unique combinations of these parameters. Region A represents a coast of low-energy and short-period waves $\left(H_{s, 50 \%}<1 \mathrm{~m} ; T_{m}<7 \mathrm{~s}\right)$, with $H_{s, 10 \%}$ values greater than $1 \mathrm{~m}$ at beaches along the southwest coast of Anglesey (Region B). Region C1 receives high-energy Atlantic swell waves, but exhibits considerable spatial variability due to varying degrees of sheltering. In the northern part of $\mathrm{C} 1$, the Bristol Channel beaches are low-energy, wind-wave dominated, while in the western part the contribution of Atlantic swell and high-energy storm events to the wave climate is at a maximum $\left(H_{s, 50 \%}\right.$ up to $\left.1.5 \mathrm{~m}\right)$. Within Region C1, fluctuations in nearshore wave height are due to local variations in beach orientation and the relative exposure. Increased shelter from the Atlantic swell source in the west (regions C2 to E) drives a wave climate transition from swell-wave to wind-wave dominance. In a number of locations wave conditions are relatively energetic $\left(H_{s, 50 \%}=1 \mathrm{~m}\right)$ due to relatively steep nearshore gradients allowing for increased wave energy transmission to the surf zone. Finally, region $\mathrm{F}$ is characterised by the semi-enclosed North Sea wave climate and experiences low-energy and short-period waves, similar to region A $\left(H_{s, 50 \%}<0.6 \mathrm{~m} ; T_{m}<7 \mathrm{~s}\right)$. Although exposed to swell from the northern Atlantic and Arctic Oceans to the north, limited amounts of swell energy reach this region due to the shallow nature of the 


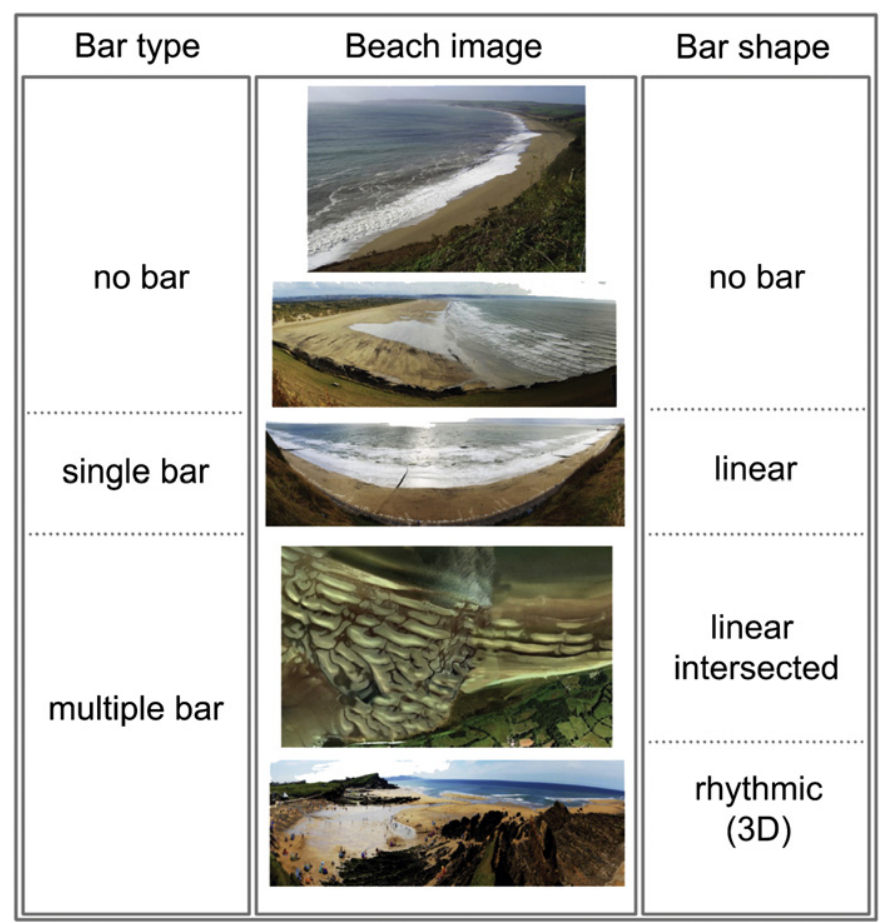

Fig. 5. Classification of bar type and shape with associated examples from remote image dataset.

southern North Sea, where water depths, even up to $100 \mathrm{~km}$ offshore of region $\mathrm{F}$, remain on average less than $30 \mathrm{~m}$.

The average MSR over the study sites is $4.9 \mathrm{~m}$ with a standard deviation of $1.9 \mathrm{~m}$. This wide variability is largely due to the continental setting of the British Isles which are surrounded by constricting channels and semi-enclosed seas, modifying the north Atlantic tidal oscillation. Fig. 6 highlights these variations, in particular showing the results of tidal constriction in the Bristol Channel (region C1), squeezing the MSR at the selected beach sites above $10 \mathrm{~m}$, as well as the effects of a degenerative amphidromic point, positioned inland of Bournemouth on the coast of southern England (region E), where a microtidal regime is observed with MSR values as low as $1.2 \mathrm{~m}$. A steady regional transition of MSR can be observed from $9.8 \mathrm{~m}$ in the Bristol Channel (Minehead) to $1.4 \mathrm{~m}$ in the English Channel near Bournemouth (Fishermans Walk). Another along-coast transition occurs along the east coast of England where MSR increases northwards from $1.9 \mathrm{~m}$ to $6.4 \mathrm{~m}$, away from the amphidromic point located in the eastern English Channel. Due to the large variability in wave/tide conditions, a large range of beach types is represented in the data set. Fig. 7 shows examples of seven beaches covering the complete spectrum from reflective to dissipative morphotypes. Additionally, a range of bar types is present in the data set, from single two-dimensional sub-tidal bars, to three-dimensional bar/rip morphology, to multiple intertidal bars.

Bar morphology plays an integral part in determining the beach type. Broken down into presence/absence, number of bars and threedimensionality, Fig. 8 maps the distribution of the simplified bar characteristics as observed from available remote imagery and field visits. The swell dominated regions of the west coast of England is the only area where strongly three-dimensional bar systems were observed, and these were generally associated with rhythmic transverse bar/rip systems (Austin et al., 2010). Beaches with few or no bar features were predominantly found in lower energy and/or wind-wave dominated locations. Multiple bar systems were found in macrotidal, and predominantly low-energy environments in regions of sediment abundance associated with ebb-tidal deltas at estuary mouths (van Houwelingen et al., 2006). Observed cases of single linear bars were few; in all cases they were in micro- to mesotidal regimes in Poole Bay and southern Norfolk.
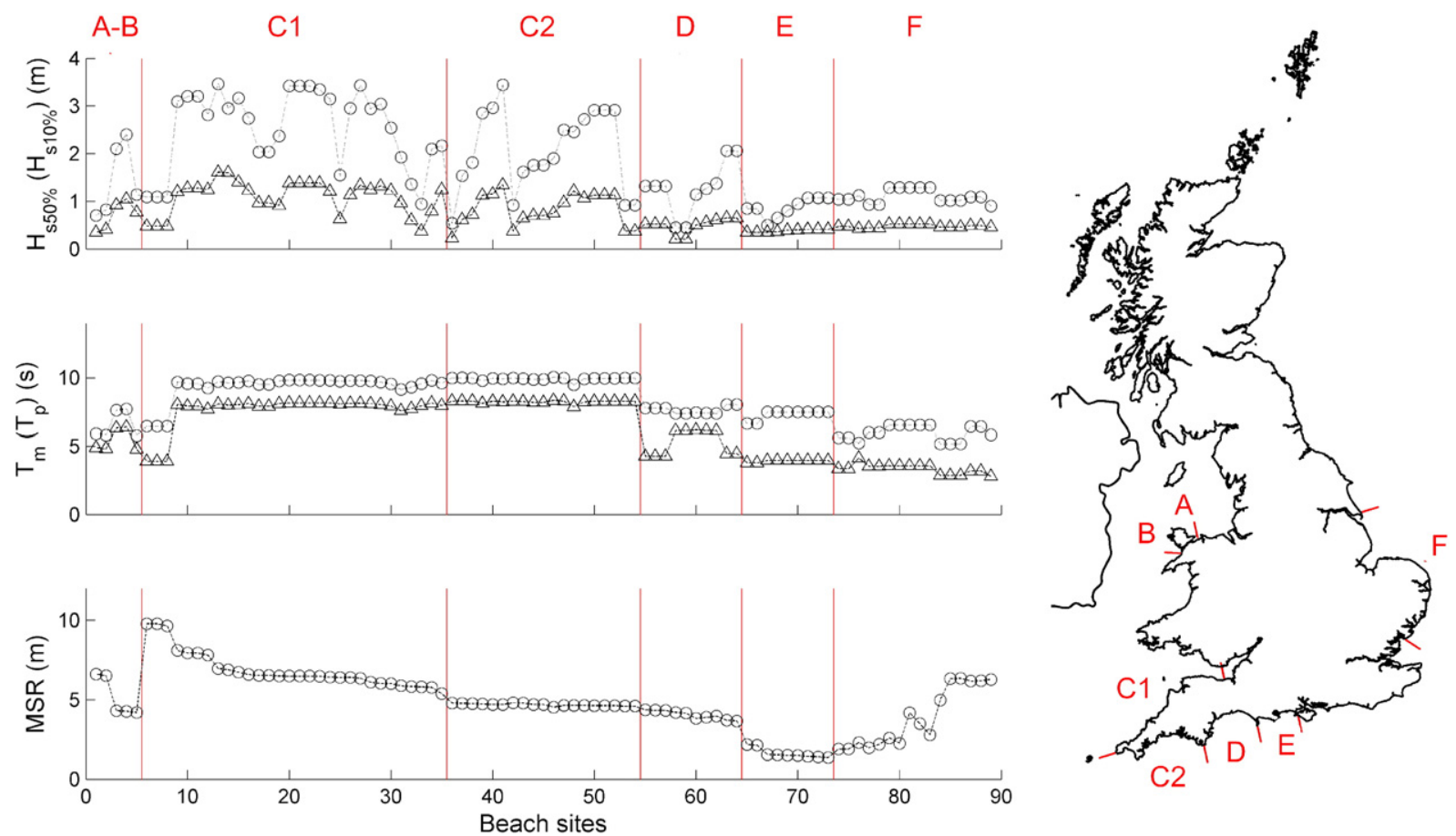

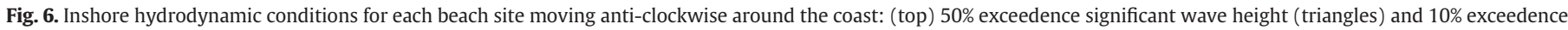

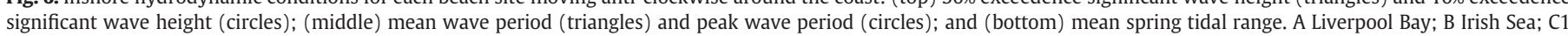
Atlantic southwest (north coast); C2 Atlantic southwest (south coast); Lyme Bay; Channel Coast; East Coast. 

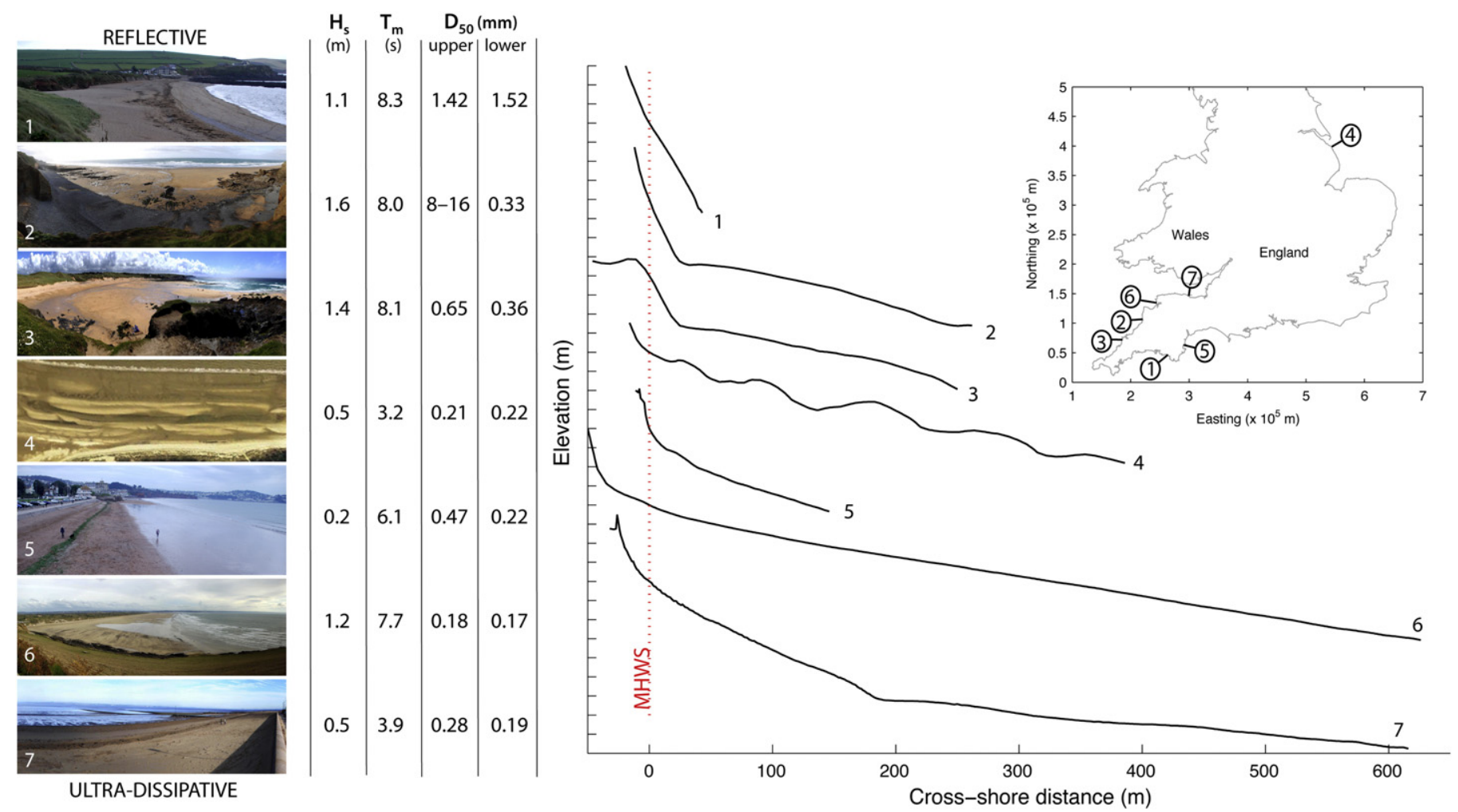

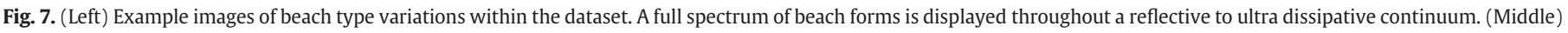

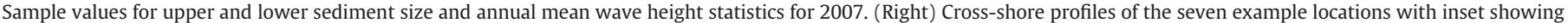
national context.

\section{Grouping of the beaches}

\subsection{Identification of beach groups though cluster analysis}

For each beach, 24 variables were extracted from the morphological, sedimentological and hydrodynamic data. However, correlation analysis revealed that a large number of variables are closely related (e.g., beach gradient and width; $H_{s, 50 \%}$ and $H_{s, 10 \%}$ ) and a large number of redundant variables were excluded from the data set. Only the 9 variables listed in Table 1 were considered in further analysis. As a technique for identifying structure within a multivariate dataset, cluster analysis has been successfully employed in previous research in the field of beach morphodynamics and classification (Hegge et al., 1996; Travers, 2007). Grouping of these ordinal and nominal data was computed using the Unweighted Pair-Group Method with Arithmetic Mean (UPGMA) and Gowers General Similarity Coefficient (Gower, 1971; Everitt et al., 2001). The output of the agglomerative hierarchical clustering analysis is expressed in the form of a hierarchical tree (Middleton, 2000). The inclusion of categorical (e.g., bar type), as well as continuous (e.g., wave height), variables within the dataset creates some limitations in the methods available to calculate the similarity or distance measures between samples. Gowers General Similarity Coefficient was selected because it is able to deal with mixed data types (e.g., Ramsay et al., 2006). A wide range of hierarchical clustering methods are available, this analysis applied a range of techniques and UPGMA provided the best results. Selection of the optimum number of groups for the particular application is a critical stage in cluster analysis. Although there are many documented ways to perform this statistically (Chatfield and Collins, 1980), logic and experience of the dataset in question must be employed when analysing the results of the final cluster analysis. In practice this means that the onus remains on the researcher to select a realistic level that is most appropriate to the underlying research question.
The beaches were grouped through cluster analysis on the basis of profile geometry, bar characteristics, sedimentology and wave/tide climate using the variable listed in Table 1 . Analysis of the dendrogram, the graphical product of the cluster analysis and its associated agglomeration levels (Fig. 9), enabled the final grouping of beaches. From the cluster analysis, 9 beach groups were defined at the $80 \%$ similarity level. This cut-off level was selected with knowledge of the beaches in mind and represented the most appropriate resolution of classes for the number of beaches and their observed morphodynamic variability, as well as considering similarity levels where sharp increases in agglomeration occur.

The structure of the resultant beach groups was further examined using a method of non-metric multi-dimensional scaling (MDS), introduced by Shepard (1962) and Kruskal (1964). This is just one of a suite of multivariate tools designed to represent the samples in a data set in a reduced dimensional space (usually two-dimensional) to aid data summarisation and was chosen due to its capacity to handle mixed data types. MDS represents the beaches as points in low-dimensional space such that the relative distances between the points are in the same rank order as the relative dissimilarities from the similarity matrix; therefore, the proximity of beaches within an MDS defines their similarity in community composition. The measure of goodness-of-fit of the MDS ordination is termed the stress value, which ranges from 0 to 1 . A stress value of 0 represents perfect ordination. 2D stress levels of 0.1 are considered to indicate excellent ordination (Clarke and Gorley, 2006).

The result of the two-dimensional MDS ordination is shown in Fig. 10 and confirms the significance of the clustering and the level of dissimilarity between beach groups. The associated stress of 0.1 indicates a good ordination with limited additional information being gained through a higher-dimensional ordination. The graphic ordination displays a reasonable level of separation within the defined beach groups ( $80 \%$ separation from Fig. 9 represented as dashed line), with the exception of groups 1, 2 and 4 which exhibit some overlap. The MDS 

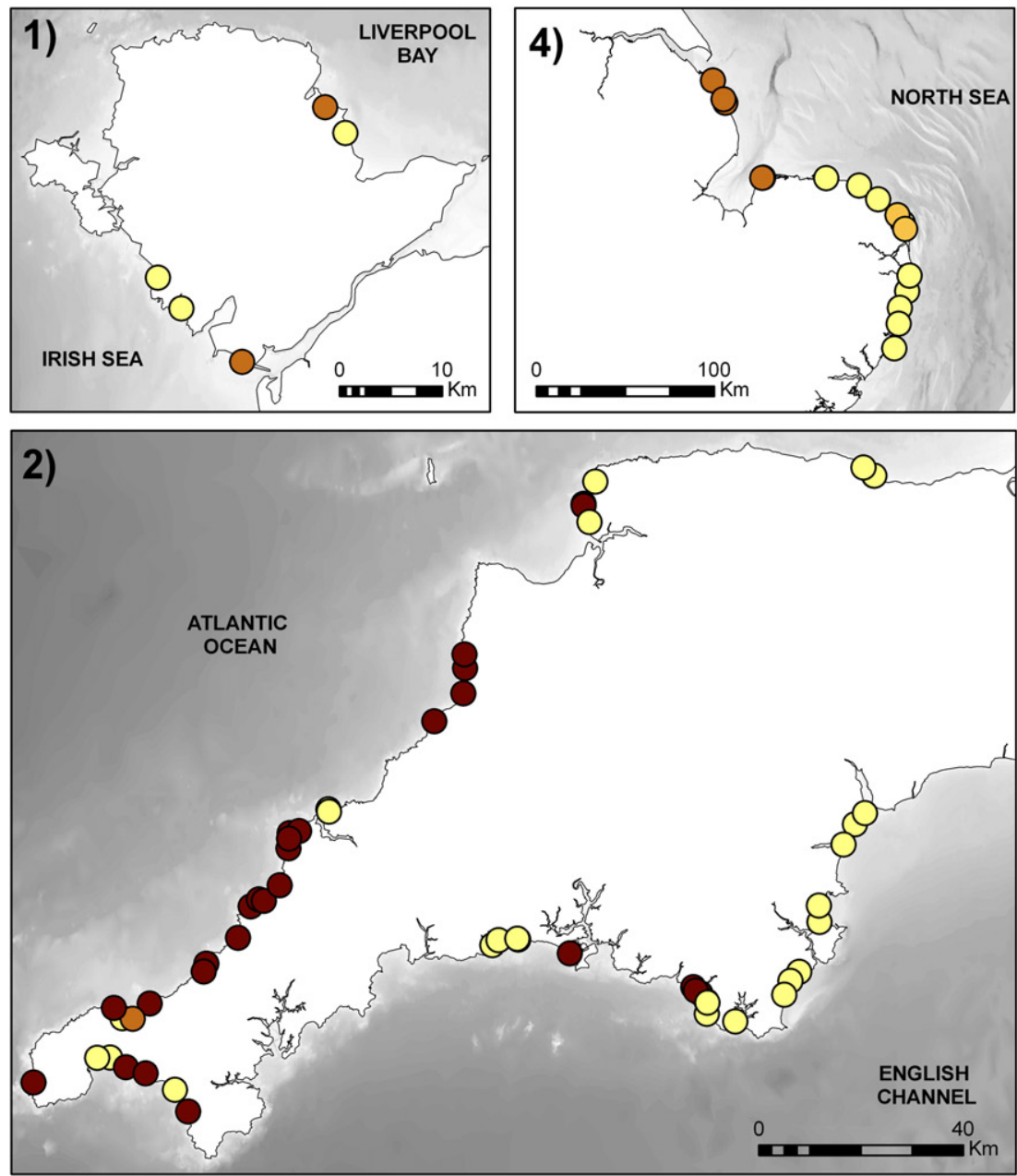

3)
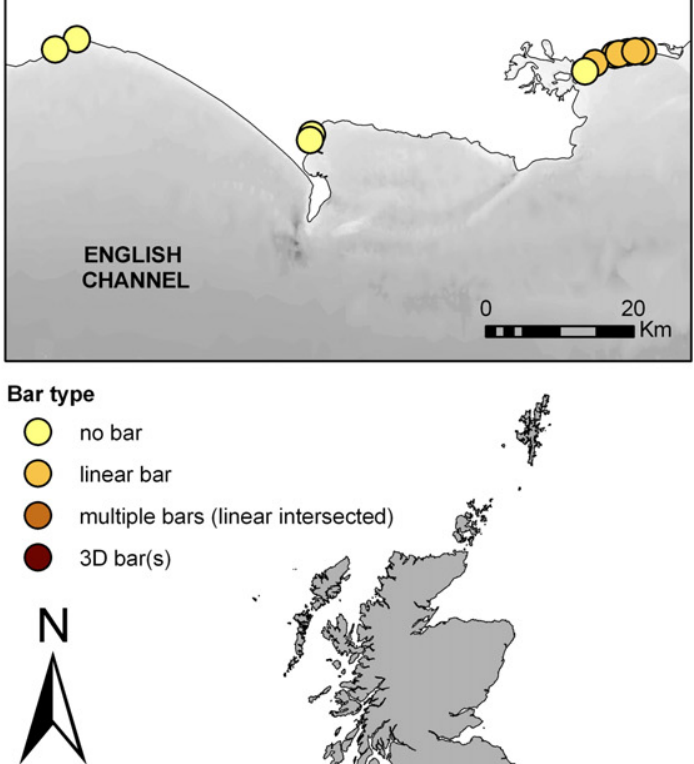

Fig. 8. Map of the study regions illustrating the distribution of bar types around the study beaches. Terminology refers to Fig. 5 .

results confirm that there are clear distinctions in morphological, sedimentological and forcing characteristics between the beach groups.

Before discussing each of the identified beach types and their association with environmental conditions, it must be borne in mind that some of the associations arise from the limitations in the data set. For example, most high-energy beaches in the data set experience highmacrotidal ranges, while many low-energy beaches are lower macro- to mesotidal.

\subsection{Characterisation of beach groups}

To assist with the interpretation of the identified beach groups, the range of values for the morphological, sedimentological and hydro-

Table 1

Parameters and associated units and value ranges included in cluster analysis and beach classification.

\begin{tabular}{llll}
\hline Term & Units & Range & \\
\cline { 3 - 4 } & & $\min$ & $\max$ \\
\hline$H_{s, 50 \%}$ & $\mathrm{~m}$ & 0.4 & 1.6 \\
$T_{m}$ & $\mathrm{~s}$ & 2.8 & 8.3 \\
MSR & $\mathrm{m}$ & 1.4 & 9.8 \\
Slope (total) & $\mathrm{deg}$ & 0.5 & 9.7 \\
Slope (segments) & $\mathrm{deg}$ & 0.2 & 14 \\
$D_{50}$ (upper) & $\mathrm{mm}$ & 0.15 & 26 \\
$D_{50}$ (lower) & $\mathrm{mm}$ & 0.14 & 21 \\
Bar type & Nominal & None & Multiple \\
Bar shape & Nominal & Linear & Rhythmic 3D \\
\hline
\end{tabular}

dynamic parameters associated with each beach were considered in MDS space (Fig. 11). In these plots, the beaches are plotted in MDS space with the size of the symbols proportional to the parameter values. Clear trends in parameter values can be seen across the groups. Beach slope, which largely controls the reflective or dissipative nature of the surf zone, and sediment size, which is strongly and positively related to beach gradient, contributes to the definition of clustered groups along the x-axis of the MDS plots (increasing from left to right). Wave height, on the other hand, contributes to separation between groups with common slope characteristics and varies mainly along the $y$-axis of the MDS plots (increasing from bottom to top). Mean spring tide range and wave period varies diagonally across the MDS plots (increasing from the lower-right to the upper-left).

The variability in bar occurrence, number and shape across the different beach groups was also investigated in MDS space (Fig. 12). Practically all beaches in a group are characterised by the same bar morphology (or absence of bars). The only exception is group 6; this group is dominated by three-dimensional, multiple, intertidal bar morphology, but includes one non-barred and one single barred beach.

So far, the characteristics of the identified beach groups have been investigated in MDS space using single parameters. Fig. 13 explores the morphodynamic variability across the beach groups using the surf scaling parameter $\varepsilon$, given by $2 \pi^{2} H^{2} / g T^{2} \tan ^{2} \beta$. This parameter is widely used for quantifying surf zone morphodynamics due to its ability to discriminate between reflective and dissipative beach states (Carrier and Greenspan, 1958), because it includes beach gradient $\tan \beta$ as well as wave steepness $H / T$. The parameter is less useful in 


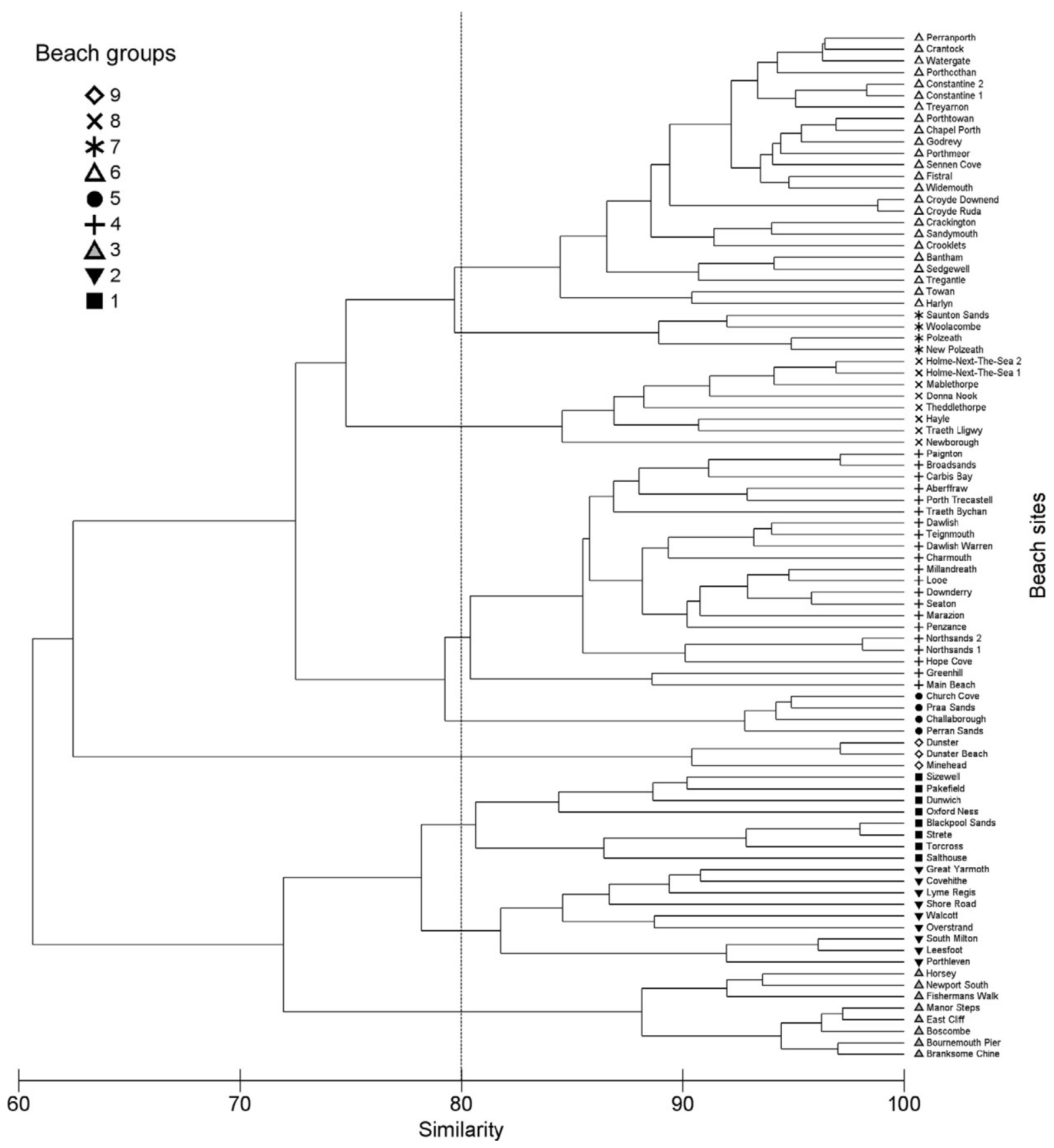

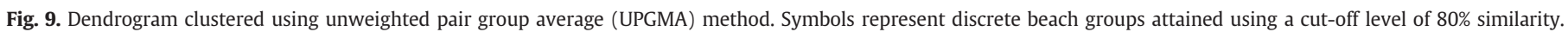
Numbering is arbitrary and represents a coarse reflective to dissipative order to aid further interpretation.

distinguishing amongst the barred, intermediate beach types (Bauer and Greenwood, 1988). The full morphodynamic range of $\varepsilon$ values (from $<2.5$ to $>300$ ) is represented in the data set with most groups being characterised by a relatively narrow range of $\varepsilon$ values. Most beaches fall in the dissipative category $(\varepsilon>20)$, with only 26 intermediate beaches $(2.5<\varepsilon<20)$ and 3 reflective beaches $(\varepsilon<2.5)$.

\subsection{Interpretation of beach groups: identification of beach types}

Application of any clustering technique to a multivariate data set will result in a solution of structured groups regardless of whether real grouping in the data exists. MDS ordination gives insight in the within- and between-group variability in the values of the parameters that form the basis of the clustering, but the resulting groups still require meaningful interpretation, i.e., the beach groups will need to be transformed into beach types. To assist with the morphodynamic description of the different beach groups, Fig. 14 shows examples of each of the beach type.

Based on group morphometric, sedimentological and hydrodynamic characteristics and using where appropriate the terminology deployed by Wright and Short (1984) and Masselink and Short (1993), the identified beach types are as follows.

\subsubsection{Reflective (low-energy): $R(L E)$ (group 1)}

Highly reflective, steeply sloping beaches with slope angles ranging from $4^{\circ}$ to $10^{\circ}$. Beach sediment is characterised by medium to coarse gravel on the upper and lower beach face $(>50 \%$ gravel content throughout). The coarse nature of sediments is a significant controlling factor in beach type within this group. These beaches typically comprise a step feature at the base of the swash zone and 


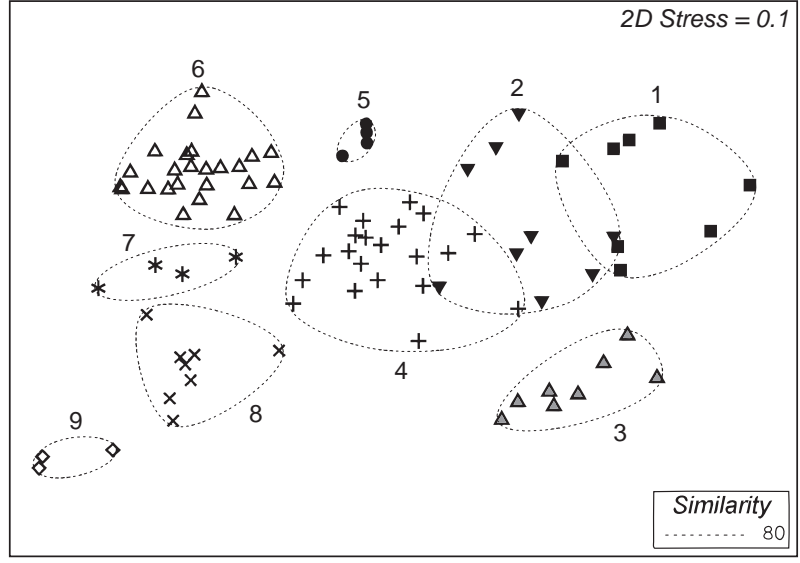

Fig. 10. MDS ordination of beach sites that represents rank order similarities in a twodimensional space. Symbols and associated numbers indicate beach groups generated through cluster analysis and dashed lines represent the groupings at the $80 \%$ similarity level (Fig. 9). The value for 2D stress provides a measure of goodness-of-fit of the MDS ordination (top right).

beach cusps may be present on the upper beach, occasionally fronted by a shallow sub-tidal terrace (within east coast region). Sampled beaches occur in low energy wind-wave dominated regions of Lyme Bay and the East Coast $\left(H_{s, 50 \%}=0.4-0.5 \mathrm{~m}, T_{m}=3-4 \mathrm{~s} ; T_{p}=5-8 \mathrm{~s}\right)$. Tides range from micro- to macrotidal (MSR $=1.9-5 \mathrm{~m}$ ). Examples of this beach type in England include Porlock, Someset (Jennings et al., 1998), Slaughden, Suffolk (Pontee et al., 2004) and Dungeness, Kent (Plater et al., 2009).

\subsubsection{Reflective (high-energy): $R(H E)$ (group 2)}

Reflective, steeply sloping beaches with inter-tidal slopes of $5^{\circ}$ to $7^{\circ}$. Grain sizes range from medium sand to gravel (commonly $10-15 \%$ gravel content). This group incorporates low to high energy beaches $\left(H_{s, 50 \%}=0.4-1.2 \mathrm{~m}\right)$ with a greater exposure to long period swell waves $\left(T_{m}=4-8 \mathrm{~s} ; T_{p}=7-13 \mathrm{~s}\right)$. These beaches are found along the southwest, south and exposed east coasts of England occurring in micro- to macrotidal environments (MSR $=1.6-4.7 \mathrm{~m}$ ), which are largely sediment limited with respect to gravel. Examples of this beach type include Chesil beach, Dorset in England (Bray, 1997) and mixed sand and gravel beaches of the east coast of the South Island, New Zealand (Jennings and Shulmeister, 2002).

\subsubsection{Linear sub-tidal barred: STB (group 3)}

These intermediate beaches have a predominantly reflective beachface with intertidal slopes of $1-7^{\circ}$ and are characterised by the presence of a linear sub-tidal bar and shoreward alongshore trough or terrace, which extends to the foot of the reflective upper beach. Bar formations can occasionally exist in the lower intertidal zone. Beach sediments are typically composed of medium to coarse sand. All beaches exist in low energy wind wave dominated $\left(H_{s, 50 \%}=0.4-\right.$ $\left.0.5 \mathrm{~m} ; T_{m}=3.5-4 \mathrm{~s} ; T_{p}=6.5-7.5 \mathrm{~s}\right)$, micro- to lower mesotidal environments (MSR $=1.4-2.8 \mathrm{~m}$ ) along the south (Poole Bay) and east coasts of England. Morphological similarities can be drawn with the classic incident scaled linear single-barred beach state first identified by Wright and Short (1984) and later reviewed by Lippmann and Holman (1990) and termed Ridge-Runnel and Incident Scaled Bar, respectively. These beach and bar states are observed in microtidal beaches worldwide, associated with the reflective, twodimensional end of the intermediate beach type spectrum, although there is no evidence here that the STB beaches in this study experience infragravity scaled, down-state dissipative transitions identified throughout intermediate beaches of New South Wales in Australia (Short, 1979a; Wright et al., 1979). Factors leading to the maintenance of bar state may include the absence of infragravity waves and the proximity of these sites to regions of higher tidal ranges and hence significant alongshore tidal flows.

\subsubsection{Low-tide terrace/non-barred dissipative (low-energy): LTT-D(LE) (group 4)}

This group represents variants of a low-tide terrace morphotype (Masselink and Short, 1993) characterised by a distinct break in slope marking a transition from a steep reflective upper beach to highly featureless dissipative lower beach, with no significant bar formations. The group represents a bar-less transition through intermediate and dissipative regimes with intertidal slopes ranging from 0.5 to $3^{\circ}$. The prominence of the steep upper beach controls reflectivedissipative end member morphologies. Sediment size ranges from medium-to-coarse sand to gravel in the upper beach with the gravel fraction reaching up to $50 \%$ in some cases, and a lower beach of fineto-medium sand with the coarse fraction occasionally reaching up to $25 \%$. In the majority of cases, a textural discontinuity was associated with a break in slope and a low-tide terrace and groundwater seepage face (Turner, 1993), which is reported as being commonplace within high-latitude coasts (Carter, 1988). The group has a low-energy mixed wave climate $\left(H_{s, 50 \%}=0.2-1.1 \mathrm{~m} ; T_{m}=4-8 \mathrm{~s} ; T_{p}=6-10 \mathrm{~s}\right)$. These beaches occur in meso- and macrotidal settings (MSR $=2.1-6.6 \mathrm{~m}$ ). Examples of this beach type also occur in Wales (Liverpool Bay, Irish Sea) and southwest, south and Lyme Bay regions of England. Reflective end member resembles the composite gravel beach form described by Jennings and Shulmeister (2002) for beaches in New Zealand, while the more dissipative forms share similarities to the Australian low energy Reflective + Low-Tide Terrace and UltraDissipative beach types described by Short (2006) which he commonly found in Queensland and north Western Australia, respectively.

\subsubsection{Low-tide terrace and rip: $L T T+R$ (group 5)}

These high energy intermediate beaches have a low-tide terrace form in addition to three-dimensional bar systems within the lower inter-tidal and sub-tidal zones, often characterised by rip current activity. Inter-tidal beach slopes range from $1.5^{\circ}$ to $3^{\circ}$, comprised of composite steep reflective upper and intermediate/dissipative flat lower beach slopes. Sediments are medium sand size with negligible coarse material $(<5 \%)$. Importantly, the wave climate is characterised by significantly higher energy than group $4\left(H_{s, 50 \%}=0.7-1.4 \mathrm{~m}\right.$; $\left.T_{m}=8 \mathrm{~s} ; T_{p}=10 \mathrm{~s}\right)$, specifically characterised by a large increase in $H_{s, 10 \%}(1.8-3.5 \mathrm{~m})$ and the potential for an infragravity controlled surf zone. These sampled beaches occur within a macrotidal $(4.6-4.7 \mathrm{~m})$ regime and are a collection of beaches within the southwest coast of England commonly identified by dynamic profile morphology and seasonal adjustment. Examples of the LTT $+\mathrm{R}$ beach type are found internationally along the Aquitaine coastline, southwest France (Castelle et al., 2007) where the full spectrum of two- and threedimensional intermediate bar states can be observed.

\subsubsection{Low-tide bar rip: LTBR (group 6)}

With slopes of $0.5-1.5^{\circ}$, and intertidal zones $200-450 \mathrm{~m}$ wide, these macrotidal beaches can be considered dissipative in overall nature with significant low-tide bar/rip systems and limited but occasional berm development. Beach sediments are commonly seaward fining, well sorted, medium to coarse sand. Occasionally a relict or limited local gravel fraction is present as part of a steeper upper beach section. Although common in overall slope, this group exhibits a range of profile forms from those approaching a low-tide terrace to those closer to a dissipative beach. Representing the largest sample group, these high-energy $\left(H_{s, 50 \%}=0.8-1.6 \mathrm{~m} ; T_{m}=8 \mathrm{~s}\right.$; $\left.T_{p}=9-10 \mathrm{~s} ; H_{s, 10 \%}=1.6-3.5 \mathrm{~m}\right)$ beaches occurred on the macrotidal (MSR $=4.5-8 \mathrm{~m}$ ) west and southwest coasts of England. Large tidal translation rates cause pronounced tidal non-stationarity and smoothing of morphological features throughout the mid-tidal region. 


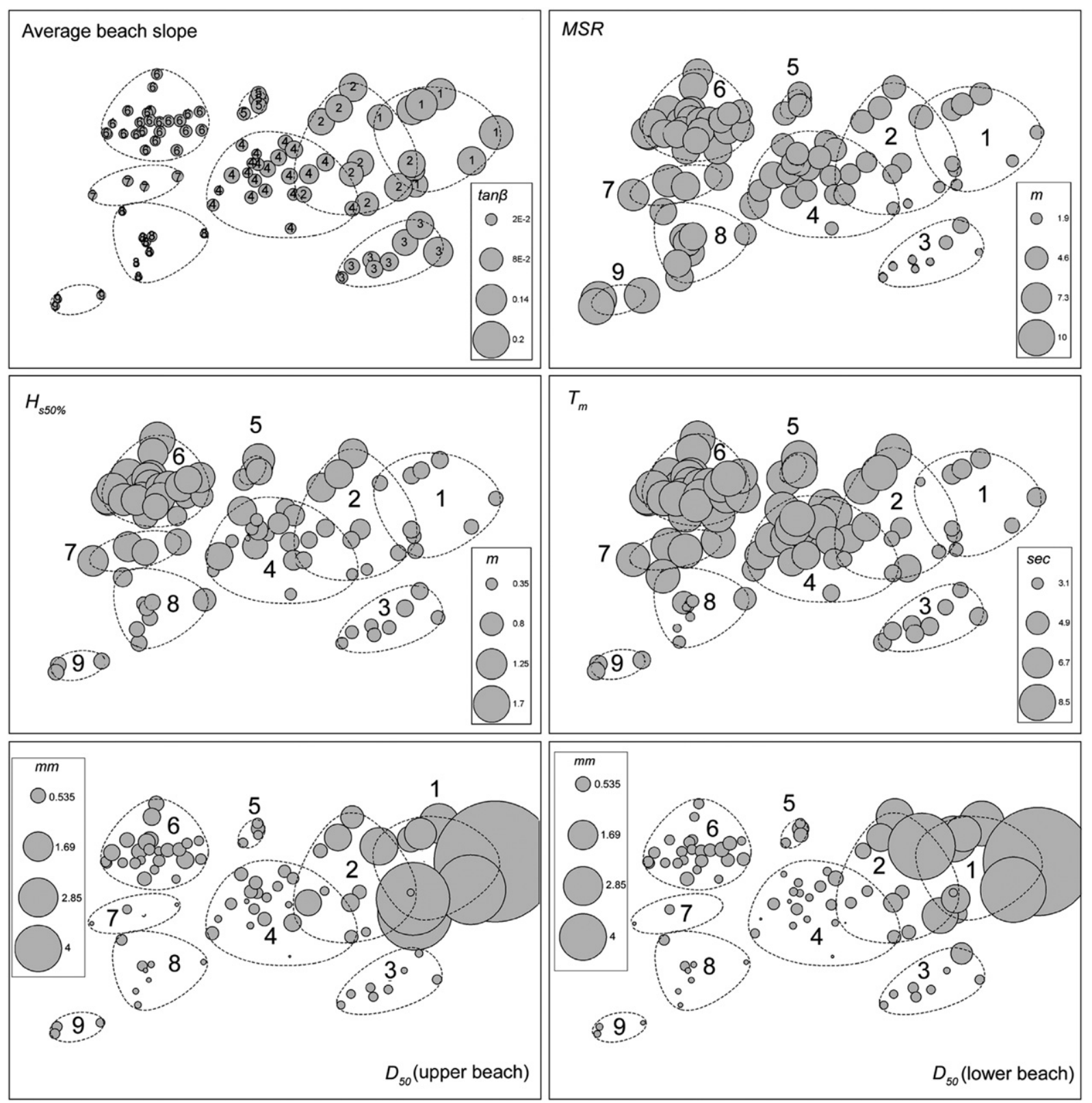

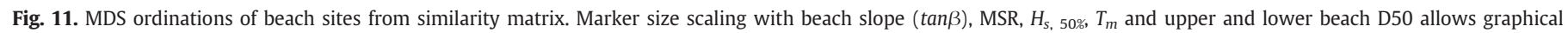
assessment of trends within and between groups. Numbers indicate beach group association. Dashed lines represent the groupings at the $80 \%$ similarity level (Fig. 9 ).

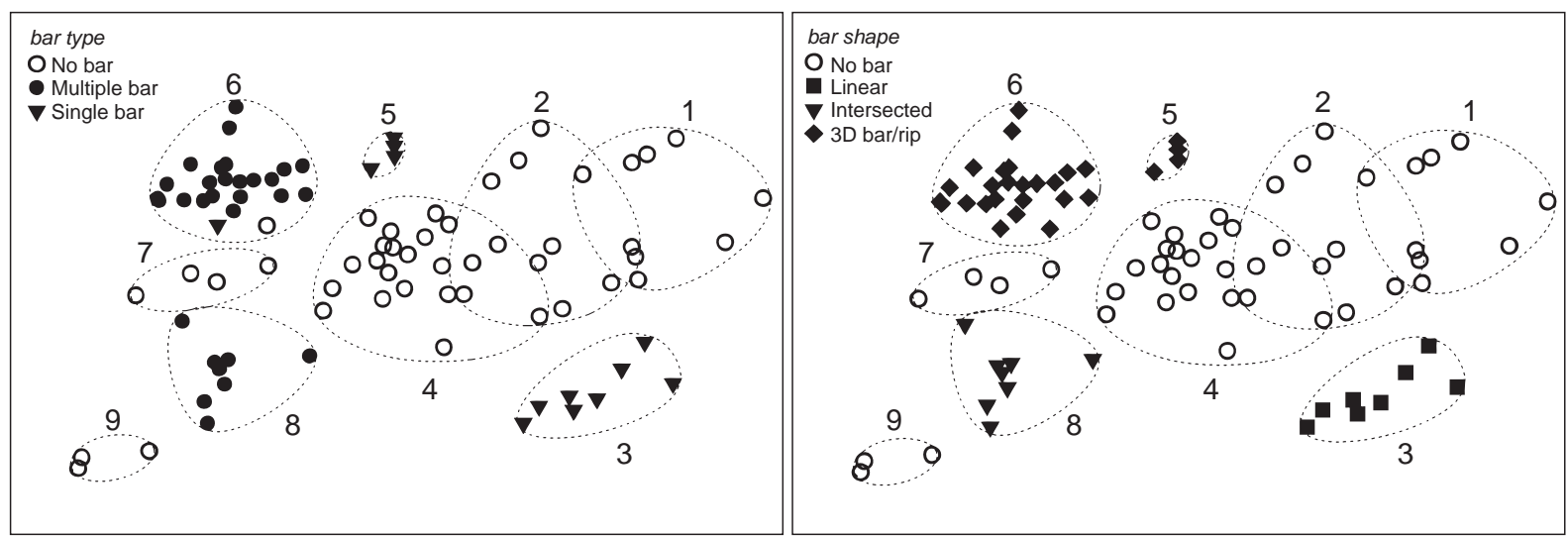

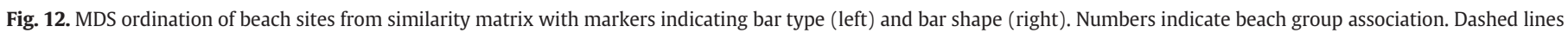
represent the groupings at the $80 \%$ similarity level (Fig. 9). 


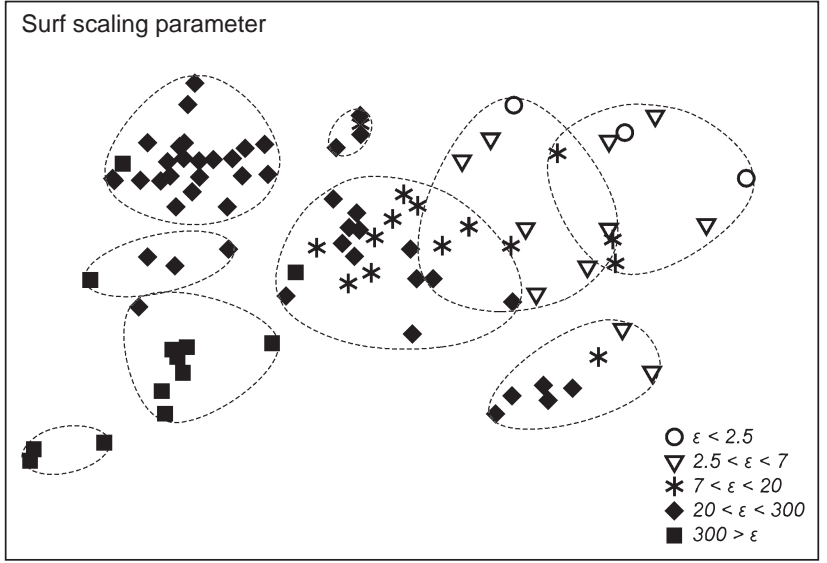

Fig. 13. MDS ordination of beach sites from similarity matrix, with markers indicating values of the surf scaling parameter describing wave dissipation characteristics in the surf zone. Numbers indicate beach group association. Dashed lines represent the groupings at the $80 \%$ similarity level (Fig. 9). Sites represent full range of values of the surf scaling parameter from reflective $(\varepsilon<2.5)$ through intermediate $(2.5<\varepsilon<20)$ to dissipative $(\varepsilon>20)$.

Low-tide bar and rip current morphologies display many characteristics of high-energy barred micro- to mesotidal intermediate beaches in literature (e.g., Wright and Short, 1984; Masselink and Short, 1993). Other UK examples include Runkerry Beach, Co. Antrim, Northern Ireland (Shaw, 1985).

\subsubsection{Non-barred dissipative (high-energy): $N B D(H E)$ (group 7)}

These beaches are almost entirely dominated by a flat, wide, featureless intertidal zone. Beach slopes are very gentle $\left(0.5-1^{\circ}\right)$ and composed of homogeneous fine to medium sands. In some cases, a relatively small reflective coarse upper beach may be present due to locally derived or relict coarse sediments. Beaches in this group are located on high-energy swell wave dominated coasts $\left(H_{s, 50 \%}=1-\right.$ $\left.1.2 \mathrm{~m} ; H_{s, 10 \%}=2-3 \mathrm{~m} ; T_{m}=8 \mathrm{~s} ; T_{p}=9-10 \mathrm{~s}\right)$ and occur in highenergy upper-macrotidal regions (MSR $=6.5-8 \mathrm{~m}$ ). Large tidal ranges and fine sediments create very wide $(300-700 \mathrm{~m})$ intertidal zones where the rate of tidal translation of surf zone processes inhibits the formation of any bars. Examples of this beach type include Pendine Sands, Carmarthenshire, Wales (Jago and Hardisty, 1984) and Rossnowlagh, Donegal, Ireland (Jackson et al., 2005).

\subsubsection{Multiple inter-tidal barred: MITB (group 8)}

Beaches are typically characterised by very gentle slopes $(0.5-$ $1.5^{\circ}$ ) with intertidal widths of $300-800 \mathrm{~m}$ and characterised by a series of shore-parallel bars (3-6) that are dissected by shoreperpendicular drainage channels that occur throughout the intertidal zone. The height of the intertidal bars (crest-to-trough elevation difference) does not exceed $1 \mathrm{~m}$. Sites occur in environments where sand is fine-to-medium throughout (samples from bar crests). Sites are found in low-energy wave climates with $\left(H_{s, 50 \%}=0.4-0.8 \mathrm{~m}\right.$; $\left.H_{s, 10 \%}=0.8-1 \mathrm{~m} T_{m}=3-5 \mathrm{~s} ; T_{p}=5-6.5 \mathrm{~s}\right)$. The only exception to this is Hayle $\left(H_{s, 10 \%}=1.3 \mathrm{~m} T_{m}=7.5 \mathrm{~s}\right)$ where significant contribution of wave climate is from medium energy swell waves. Study sites occurred in macrotidal environments (MSR $=4.2-6.5 \mathrm{~m}$ ) throughout west, northwest and east coast regions. The occurrence of multiple inter-tidal barred beaches appears to be associated with abundant sediment sources, often in proximity to ebb-tide deltas of estuaries occurring throughout the coastal regions. This type of inter-tidal bar morphology is the same as the ridge and runnel topography described by King and Williams (1949) and described as low-amplitude ridges in a review of intertidal bar morphology by (Masselink et al., 2006). Examples of these beach types occur throughout the north Linconshire coast (van Houwelingen et al., 2006) and include Blackpool
Beach, northwest England, and Leffrinckoucke Beach, north France (Masselink and Anthony, 2001) as well as Wissant Bay, north France (Sedrati and Anthony, 2007).

\subsubsection{Transition to tidal flats: TTF (group 9)}

These sites have flat and wide intertidal zones of $800-1000 \mathrm{~m}$ with slopes of c. $0.5^{\circ}$ and no bars. The lower intertidal zone of these beaches are even flatter with slopes of $0.3^{\circ}$ to $0.4^{\circ}$. Sediments are medium sand in the upper beach (occasionally coarse sand/gravel fraction is present) and fine- to very fine sand on the lower beach. This group represents a small sample of beaches limited to the megatidal Bristol Channel region $(\mathrm{MSR}=9.7 \mathrm{~m})$. Beach sites are largely tidallydominated as low-energy wave conditions commonly occur in channels and mouths of large estuaries/inlets associated extremely high tidal ranges. The semi-sheltered Bristol Channel has a lowenergy wind wave dominated wave climate $\left(H_{s, 50 \%}=0.5 \mathrm{~m} ; T_{m}=4 \mathrm{~s}\right.$; $T_{p}=6.5 \mathrm{~s}$ ). Due to the extent of the tidal range, the surf zone regimes of these beaches vary greatly from high- to low-tide. Lower beach gradients, and very wide surf zones at lower tides drive breaker height down due to bed friction (Levoy et al., 2000) increasing the tidal dominance. While at high-tide, a reduction in wave attenuation and surf zone width can lead to a more intermediate surf zone character associated with a steeper beach face. These beaches are ultradissipative and represent the transition to tidal flats as identified by Short $(1999,2006)$. Examples of these beaches worldwide are limited due the requirement of large tidal ranges. Levoy et al. (2000) observed similar beaches in megatidal regions of northern France.

\section{Beach classification model}

The identified beach types described in the previous section have much in common with those comprising the beach classification model proposed by Masselink and Short (1993), which links the occurrence of distinct beach types to values of the dimensionless fall velocity $\Omega$ and the relative tide range RTR. The model is used widely, although a number of researchers have suggested its application is not always practical in the presence of constraining or modifying conditions such as very coarse sediments, nearshore reefs, low energy conditions and geological control (Hegge et al., 1996; Sanderson and Eliot, 1999; Jackson et al., 2005). Fig. 15 plots all 92 beaches in this study in $\Omega$-RTR space in their identified groups to assess to what extent they conformed to the model of Masselink and Short (1993).

The beach sites within this study exhibit some clear distinctions in their location within the $\Omega$-RTR plot and there seems to be some agreement between the positioning of the beach types on the model of Masselink and Short (1993). In general terms, variations in $\Omega$ and RTR between the groups describe the transitions from reflective to dissipative and tide-effected to tide-dominated quite well. The most encouraging result is the appropriate classification of the low tide bar rip (LTBR; group 6) beach type. This beach type occupies a rather small morphodynamic window $(\Omega=2-5$; RTR $=3-7)$, and the LBTR beaches identified in this study appropriately plot within these boundaries.

Less successful is the positioning of the low tide terrace/nonbarred dissipative (LTT-D; group 4) beach type on the $\Omega$-RTR plot, because it seems to extend across a wide range of parameter values. Within the LTT-D group, the use of $\Omega$ and RTR appears to clearly distinguish between a low-tide terrace form dominated by a reflective upper beach and a more dissipative form where the lower dissipative terrace controls the surf zone regime throughout the majority of the tide. This range of observed beach forms can be explained by the large proportion of beaches within this group having a mixed and/or limited sedimentary environment exerting a significant local control on beach form. In essence, the LTT-D group contains a range of lowenergy beach forms with composite slopes (with the upper beach coarser than lower) that display no significant bar morphology and 


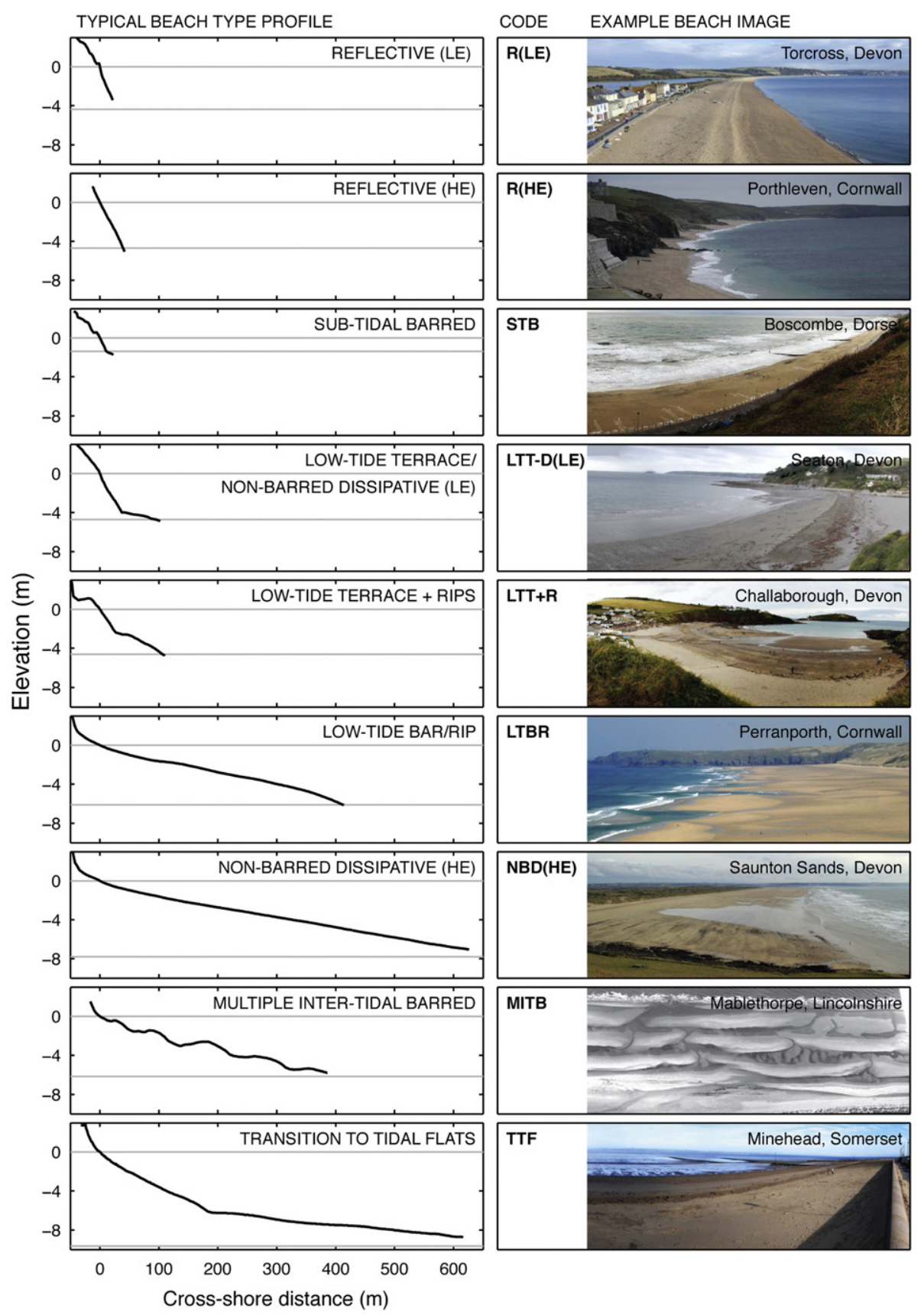

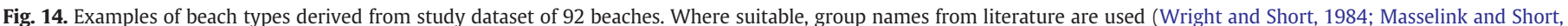

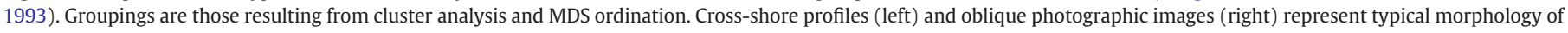
each group.

are identified by a reflective surf zone at high-water and a non-barred dissipative surf zone at low-water, under average wave conditions. Observed scatter in values for $\Omega$ and RTR within LTT-D beaches are in part attributed to parameter sensitivity to expected error levels through point sediment sampling and nearshore wave estimation within a low-energy environment.

The positioning of the high-energy reflective ( $\mathrm{R}(\mathrm{HE})$ : group 2 ) and low-energy reflective ( $R(L E)$; group 1$)$ beach types agreed well in terms of $\Omega$, but extended into higher values of RTR mostly due to higher tidal ranges. The $\mathrm{R}(\mathrm{HE})$ and $\mathrm{R}(\mathrm{LE})$ beaches generally exhibit coarser sediments than the reflective beaches of Masselink and Short (1993) and Wright and Short (1984). As seen in many of the sampled beaches, this can act to extend the fully reflective morphodynamic regime into meso- to macrotidal environments.
Although $\Omega$ is capable of describing the sequence of morphologies from R with no bars, through LTT + R and LTBR with bar/rip systems, to $\mathrm{NBD}(\mathrm{HE})$ with no bars, the STB and LTT-D beaches plot within a similar relative context and have contrasting beach morphologies. Thus, $\Omega$ appears less successful in differentiating the different bar morphologies within the intermediate beach types. Fig. 16 plots the mean parameter values for each of the beach types, and associated 25 and 75 percentiles, for $\Omega$ and RTR, but also for absolute wave energy flux (wave power) $P$, which is proportional to $H^{2} T$, given by

$P=\frac{1}{16} \rho g H_{s}^{2} c_{g}$ 

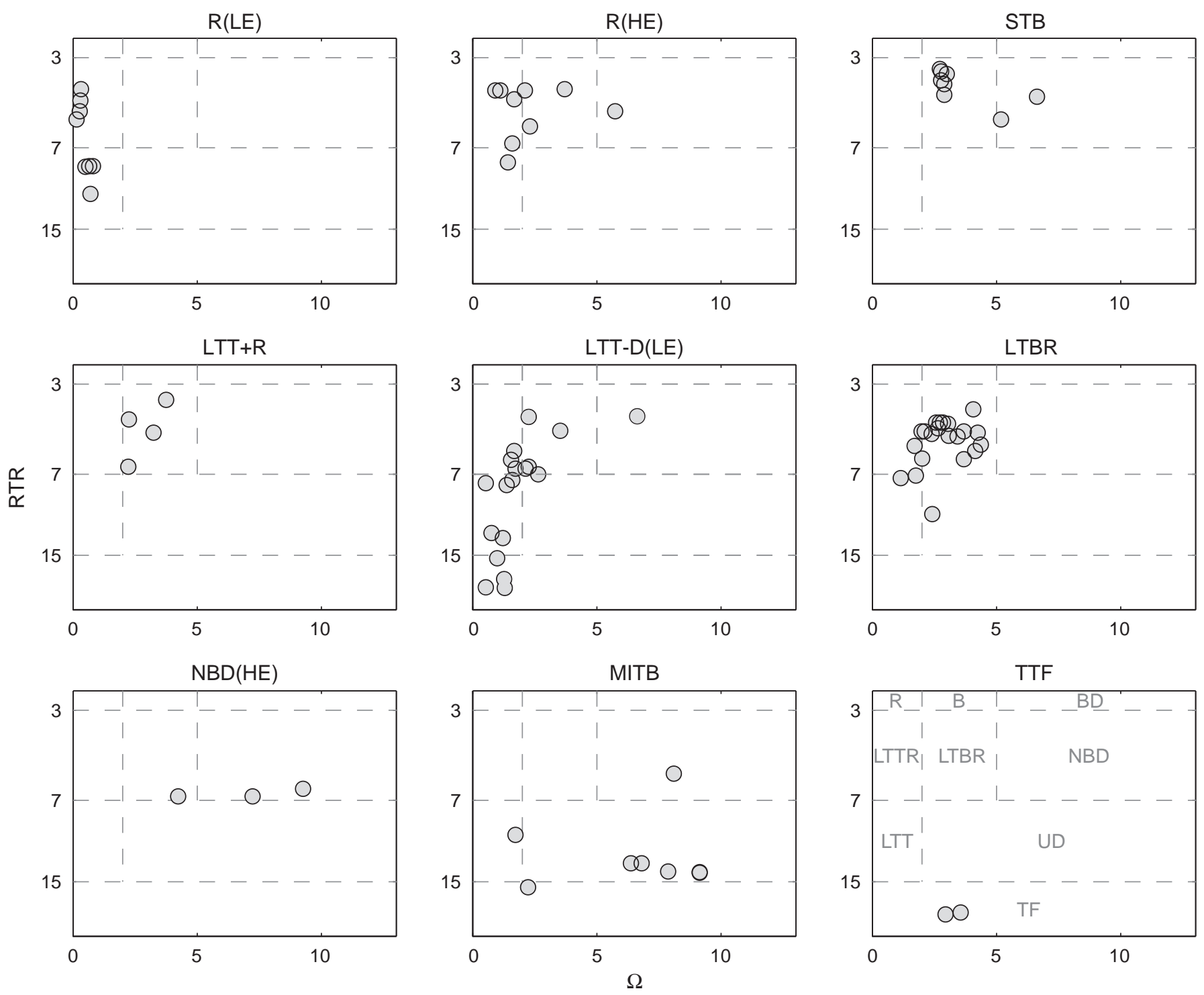

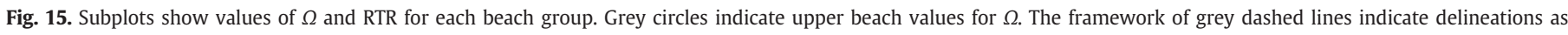

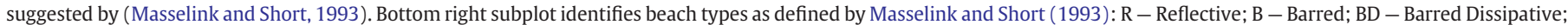
LLTR - Low-Tide Terrace + Rips; LTBR - Low-Tide Bar/Rip; NBD - Non-Barred Dissipative; LTT - Low-Tide Terrace; UD - Ultra-Dissipative; TF - Transition to Tidal Flats.

where $c_{g}$ is wave group velocity

$c_{g}=n\left[\frac{g T}{2 \pi} \tanh \left(\frac{2 \pi h}{L}\right)\right]$

in which

$n=\frac{1}{2}\left[1+\frac{2 k h}{\sinh (2 k h)}\right]$

where $\rho$ is density of seawater, $g$ is gravity, th is water depth, $L$ is wave length and $k=2 \pi / L$.

A good separation between the low and high-energy intermediate beach types is obtained in the scatter plots involving $P$. This suggests that absolute wave energy flux is an important factor in differentiating between barred and non-barred intermediate beaches within a UK context. It tentatively suggested that in order to produce three-dimensional bar/rip morphology, a threshold of $P=3 \mathrm{~kW} \mathrm{~m}^{-1}$ has to be exceeded. This threshold is identified in the dataset as the joint distribution of $H_{s, 50 \%}=0.8 \mathrm{~m}$ and $T_{m}=8 \mathrm{~s}$ where the higher wave period identifies the influence of ocean swell wave exposure to forcing conditions. Masselink and Short (1993) highlighted this issue of the potential importance of absolute wave energy level as a cautionary note in the context of their conceptual beach state model in particular in relation to bar formation.

A conceptual synthesis of the beach types, within the context of $\Omega$ and RTR, is shown in Fig. 17. Due to the important role of absolute wave energy level, beach types are broken down into two groups: those occurring in a low-energy environment, and those occurring in a high-energy environment. A wave energy threshold is used here, but it must be emphasised that the present approach is data driven and that the proposed group boundaries are a function of the selected beach sites. This synthesis is therefore not designed to be a predictive tool, rather an aid to understanding the relative contributions of wave, tide and sediment characteristics to the beach morphodynamic system. The nature of generating static boundaries between the beach types is unrealistic, and the beach types represent a dynamic spectrum subjected to local and regional variations in constraining and modifying factors. 

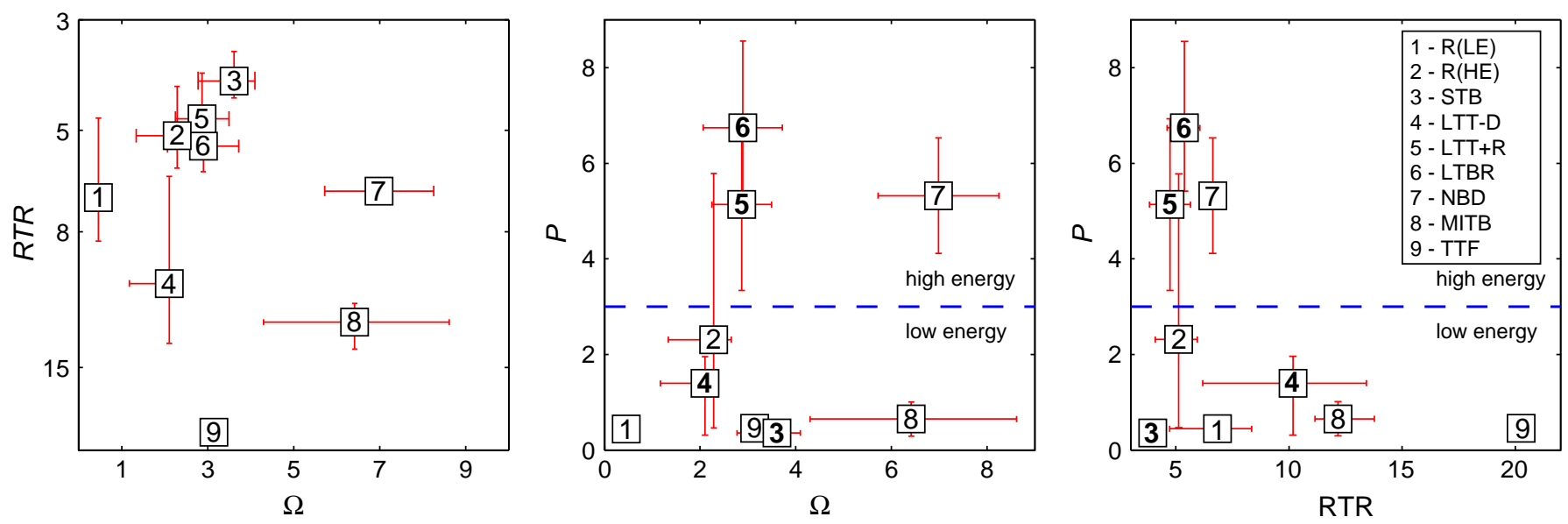

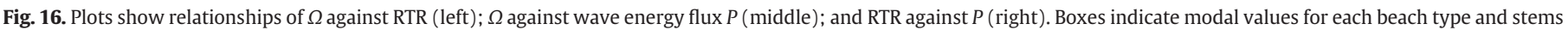

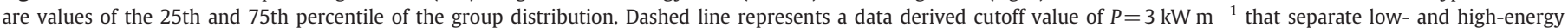

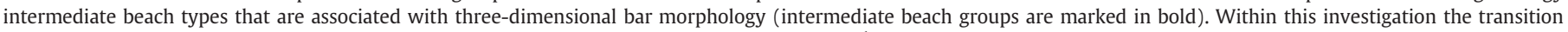

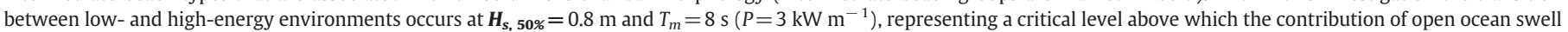
energy to the wave spectrum is sufficient to support three-dimensional infragravity scaled bar formations.

\section{Discussion}

Fig. 17 provides a synthesis of the present work by summarising the dynamic relationships between beach types in England and Wales, and their transitions in relation to the relative contribution of waves, tides and sediments. Similar to the conceptual beach model of Masselink and Short (1993) and more recently the wave- to tidedominated conceptual beach morphodynamic framework for the Australian coast by Short in the review paper (Short and Jackson,in press), the synthesis presented here considers the occurrence of the different beach types in a two-dimensional space defined by the dimensionless parameters $\Omega=H_{s} / w_{s} T$ and RTR $=\mathrm{MSR} / H_{s}$. There are, however, two key differences from Masselink and Short (1993): (1) absolute wave energy is accounted for with low- and high-energy beach types being considered separately; and (2) the resultant conceptual framework (Fig. 17) deliberately lacks clear boundaries between the different beach types.

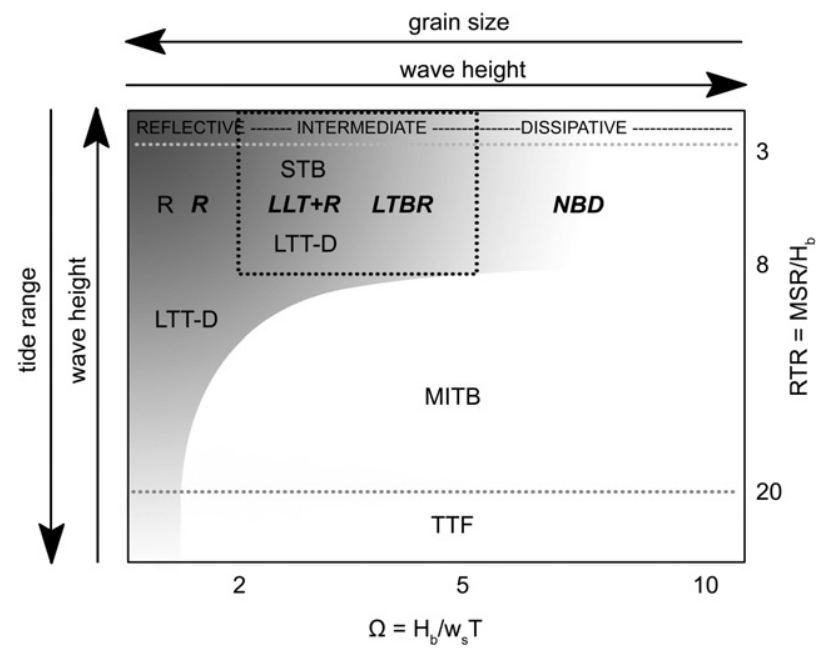

Fig. 17. Conceptual morphodynamic framework (within $\Omega$-RTR space) for sampled beaches throughout England and Wales. Dark and light shadings indicate a general transition from reflective to dissipative surf zone conditions, respectively. Bold black dashed box indicates region of intermediate beach types where high-energy conditions $\left(P>3 \mathrm{~kW} \mathrm{~m}^{-1}\right)$ are required to support three-dimensional bar formations. Beach types in bold italics exist only in a high-energy wave climate.
Clustering analysis provided a clear characterisation of the different beach types and the quantification of the wave/tide/sediment characteristics are entirely data-driven with resultant groupings providing clear morphodynamic differentiations. The overlap in $\Omega$-RTR parameter space between the different beach types reflects the observed scatter within the dataset (refer to Fig. 15) and highlights the limitations of a non-dimensional parametric approach. This scatter is attributed to the following three factors: (1) use of non-dimensional and relative environmental parameters; (2) disregarding of temporal variability in morphology and environmental conditions; (3) role of geology. These factors represent inherent limitations to the beach-type approach followed here and the data collection programme, and will be discussed in some detail below.

\subsection{Use of non-dimensional and relative environmental parameters}

The environmental parameters in Fig. 17 are non-dimensional and relative: the dimensional fall velocity $\Omega$ expresses the wave steepness in relation to the sediment size, while the relative tide range RTR is the ratio between tide range and wave height. One obvious shortcoming associated with these descriptors is that the role of absolute energy level (waves or tides), wave period and sediment size is disregarded and that similar (different) locations on the $\Omega$-RTR plot can represent different (similar) wave, tide and sediment characteristics. Thus, although non-dimensional parameters are useful for combining results from different field sites, valuable information is lost.

The importance of the intensity of wave forcing (and duration) in controlling beach state has been pointed out by Jiménez et al. (2008) and the data presented here suggest that the occurrence of threedimensional bar/rip morphology (LTT $+\mathrm{R}$ and LTBR beach types) requires wave energy conditions to exceed a certain threshold level. This threshold has been tentatively set at $P=3 \mathrm{~kW} \mathrm{~m}^{-1}$, but more data is required to refine this.

The absolute value for the wave period, rather than its relative expression $H / T$, is relevant. Globally, beaches with pronounced threedimensional bar/rip morphology appear to be restricted to highenergy, swell environments, and are much less common along coasts with a local wind-driven storm-wave climate. Contrast, for example the configuration of the inner bar systems along storm-wave dominated Dutch coast with those along the swell-dominated south Atlantic coast of France. Both coastlines experience intermediate modal $\Omega$ values and are characterised by multi-barred beaches, but whereas the Dutch inner bars are mainly linear and intersected by rip/ 
drainage channels (Short, 1992), the French inner bars are characterised by transverse bar/rip morphology (Castelle et al., 2007). Wave period may also be an important factor in the development of multiple bar morphology. For example, Short and Aagaard (1993) argue that the number of subtidal bars on beaches is related to the wave period.

The absolute tide range is also important, because it determines the intertidal beach gradient and tidal translation rates (Masselink, 1993), and therefore the degree to which bar formation is suppressed due to tide-induced non-stationarity. A large tide range also promotes the development of strong tide-driven longshore currents, especially in the troughs of beaches with multiple intertidal bar morphology (Sedrati and Anthony, 2007). Not only do such currents contribute significantly to sediment transport, but also the currents restrict the movement of sediment across the troughs, causing the troughs to serve as effective sediment transport barriers (Parker, 1975). In this context it is interesting to note that the STB beach type, although experiencing relatively low tidal ranges, occurs in regions in the immediate vicinity of large-tidal regions and are likely to be characterised by strong longshore tide-induced flows in the trough (Martín-Grandes et al., 2009). It is tempting to attribute the occurrence of the longshore bars on these beaches to the strong tide-induced currents in the trough that prevent their onshore migration and welding to the shore resulting in low-tide terrace morphology.

Finally, the absolute sediment size is relevant because it is (nonlinearly) related to the hydraulic conductivity, and hence controls the potential of seepage face formation (Turner, 1993) and the development of a low tide terrace (Turner, 1995). The LLT beach type is not defined by the low tide terrace, which is morphodynamically identical to the mid-to-lower intertidal zone of the NBD beach type, but by the presence of a steep reflective upper beach section. For a sufficiently extensive steep section to develop, Masselink and Turner (1999) suggest that a high-tide sediment size of at least $0.3 \mathrm{~mm}$ is required. The inclusion of both upper and lower sediment sizes was important to enhance the differentiation of the low-tide terrace beach form.

\subsection{Disregarding variability in morphology and environmental conditions}

The beach-type approach encapsulated by Fig. 17 assumes that the modal beach type can be linked to average dimensionless parameters that include wave/tidal/sediment characteristics. Regardless of whether the selected parameters are appropriate (Anthony, 1998), the use of time-averaged parameters disregards the variability in wave/tide/sediment conditions which drives beach change, as documented in numerous temporal beach state studies (e.g., Short, 1978, 1984; Sénéchal et al., 2009). Detailed investigations of beach type involving video monitoring (Lippmann and Holman, 1990; Ranasinghe et al., 2004) indicate that beaches respond rapidly to increasing energy conditions (up-state transitions), but adjust slowly to decreasing energy conditions (down-state transitions). Especially on low-energy beaches (Jackson et al., 2002), this asymmetry in morphological response may give rise to features that are not representative of mean wave conditions, but are the result of energetic wave conditions not accounted for by average values for $\Omega$ and RTR (Costas et al., 2005). The two beach types that are most likely to be affected by such relaxation time effects, and are hence least well described by average wave conditions, are the STB and MITB beach types.

\subsection{Role of geology}

Average wave/tide conditions and sediment size characteristics are of first-order importance in controlling beach type, and beach change is largely driven by temporal changes in wave/tide/sediment conditions (Short, 1999). However, beach morphology can also be significantly influenced by other, often site-specific, factors, and the role of geology is most frequently mentioned as being important in controlling beach morphology.

Following a comparison between observations on 25 beaches around the north coast of Ireland and the Masselink and Short (1993) model, Jackson et al. (2005) conclude that inherited geological factors appear to be more important determinants for beach morphology than contemporary dynamics. The role of geology in modulating inshore wave conditions, due to the presence of offshore outcrops or reefs (Sanderson and Eliot, 1999; Short and Woodroffe, 2009; Short, 2010), and promoting the development of headland-controlled rips in embayed beaches (Short and Masselink, 1999) is well known. Similarly, the large-scale control of geology on embayment size through dictating the size of river catchments has been pointed out by Bishop and Cowell (1997). However, if inshore wave conditions are used to characterise the wave dynamics, rather than the offshore wave climate (which is significantly modified by the offshore geology by modulating wave transformation processes), the influence of geology is mainly through its control on sediment size and availability.

As pointed out by Jackson et al. (2005), along relatively sedimentstarved coastlines, such as the north Irish coast, beaches may comprise of thin, surficial veneers of sediment over rocky or relict glacial surfaces, and are hence not able to develop to their fullest potential. In addition, beach gradients may be relatively steep due to the underlying geology. Many embayed beaches along the southwest coast of England are relatively sediment-starved, and monthly beach surveys conducted since 2006 have indicated that extreme wave conditions can result in the exposure of rocks in the intertidal zone due to offshore sediment transport (Scott et al., 2008). However, despite the lack of a continuous cover of sediment, bar morphology remains present around the low tide level and/or in the sub-tidal zone. Clearly, for characteristic beach morphologies to develop a sufficient amount of sediment is required, but a continuous sediment cover is not necessarily a prerequisite.

Abundance of coarse sediments, often associated with drift geology in higher latitudes (Orford et al., 2002), also influences the R/LTT transition. If a large amount of coarse sand or gravel is available, a steep and reflective profile can be maintained throughout the intertidal region, resulting in the $\mathrm{R}$ beach type (e.g., Orfordness, Chesil, Slapton Sands). But if the supply of coarse material is limited, the steep and coarse upper beach will be fronted by a sandy low tide terrace, resulting in the LTT beach type (e.g., Westward Ho!, Porlock). The amount of coarse sediment available is only partly related to contemporary wave conditions, but will mainly be attributable to geological factors.

An additional, and thus far unreported, consequence of the presence of relatively thin sediment veneers placed on impermeable rocky surfaces is the role of stream discharge. Practically all embayed beaches along the southwest coast of England have small streams discharging directly onto the beach. Following heavy rainfall events in the summer and over most of the winter period, a large section of these beaches are saturated. Erosive conditions tend to prevail over these beach sections, giving rise to flat and featureless morphology, and regions of stream outflow can influence rip channel morphology. On most beaches the area affected by streams is relatively limited, but on some of the smaller beaches, the stream has a dominant affect on the overall appearance of the beach.

\subsection{Concluding comments on the use of beach state models}

The synthesis presented in Fig. 17 is to all intents and purposes a model in that it represents a simplified version of reality. The datadriven model is based on analysis of beach morphology, sedimentology and wave/tide conditions of 92 beach sites in England and Wales, representing a broad selection of beach systems and hazards. The model has also been designed with a clear purpose in mind: to provide a beach classification model that can be used as the basis for 
a national beach risk assessment programme (Scott, 2009). The sitespecific and applied nature of the model represented by Fig. 17 means that it is appropriate for the locality and purpose for which it has been developed, but is less useful for wider application. It is certainly not a predictive model that can be universally used. The same argument applies to the widely-used and tested model of Wright and Short (1984), developed for the high-energy, microtidal coast on New South Wales, Australia. There is the tendency in the coastal literature to take site-specific models and test them outside the region for which they have been derived. Not surprisingly, the models are often found inadequate predictors of beach type, leading to rejection or modification of the model. In fact, in regions with large tidal range along the coastline of England and Wales, none of the intermediate beach types in the Wright and Short (1984) model are represented in the current data set. We therefore concur with Jackson et al. (2005) and urge caution in the application of the beach type approach in predicting beach morphology from hydrodynamic and sediment data. Practical, or applied, beach state models are best developed at a geographical meaningful scale; a universal beach model does not exist.

\section{Conclusions}

Detailed morphodynamic characteristics of 92 beaches within the UK were collected yielding a comprehensive multi-variate data set containing morphological, sedimentological and hydrodynamic information. Cluster analysis supplemented by MDS ordination resulted in the identification of 9 distinct beach types. Traditional morphodynamic indices $\Omega$ and RTR were found to be effective in discriminating between beach groups providing some support for the model of Masselink and Short (1993), which was derived using information from Australian beaches. However, it was found that in addition to the dimensionless parameters $\Omega$ and RTR, the absolute wave energy level is important as well in controlling beach type. A wave energy flux $P\left(\propto H^{2} T\right)$ value of $3 \mathrm{~kW} \mathrm{~m}^{-1}$ was found to differentiate between intermediate beaches with $\left(P>3 \mathrm{~kW} \mathrm{~m}^{-1}\right)$ and without $\left(P<3 \mathrm{~kW} \mathrm{~m}^{-1}\right)$ three-dimensional bar/rip morphology. Beach morphological state cannot solely be described in terms of mean wave, tide and sediment conditions, but these variables do provide a first order-explanation for the observed beach variability in nature. Beach classification models based on environmental parameters are, by necessity, simplifications and should be used as tools for understanding morphodynamic systems, rather than beach type prediction.

\section{Acknowledgements}

We would like to thank Channel Coast Observatory, Environment Agency, CEFAS and the University of Wales Bangor for providing additional data for this study. This research was supported by an HEIF2/RNLI (Royal National Lifeboat Institution) award to the University of Plymouth.

\section{References}

Admiralty, 2007. Admiralty Tide Tables. Chart NP201. Vol. Volume 1 of Admiralty Charts and Publications. United Kingdom Hydrographic Office, Taunton.

Anthony, E., 1998. Sediment-wave parametric characterization of beaches. Journal of Coastal Research 14 (1), 347-352.

Austin, M., Scott, T., Brown, J., Brown, J., MacMahan, J., Masselink, G., Russell, P., 2010. Temporal observations of rip current circulation on a macro-tidal beach. Continental Shelf Research 30 (9), 1149-1165.

Bauer, B., Greenwood, B., 1988. Surf-zone similarity. Geographical Review 78, 137-147.

Bishop, P., Cowell, P., 1997. Lithological and drainage network determinants of the character of drowned, embayed coastlines. The Journal of Geology 105 (6), 685-699.

Bradbury, A.P., Mason, T.E., Holt, M.W., 2004. Comparison of the Met Office UK-waters wave model with a network of shallow water moored buoy data. Proceedings of the 8th International Workshop on Wave Hindcasting and Forecasting. Hawaii.

Bray, M.J., 1997. Episodic shingle supply and the modified development of Chesil Beach, England. Journal of Coastal Research 13 (4), 1035-1049.
Bray, M., Hooke, J., 1997. Prediction of soft-cliff retreat with accelerating sea-level rise. Journal of Coastal Research 13 (2), 453-467.

Carrier, G.F., Greenspan, H.P., 1958. Water waves of a finite amplitude on a sloping beach. Journal of Fluid Mechanics 4, 97-109.

Carter, R.W.G., 1988. Coastal Environments: An Introduction to the Physical, Ecological, and Cultural Systems of Coastlines. Academic Press, London.

Castelle, B., Bonneton, P., Dupuis, H., Sénéchal, N., 2007. Double bar beach dynamics on the high-energy meso-macrotidal French Aquitanian coast: a review. Marine Geology 245 (1-4), 141-159.

Chappell, J., Eliot, I., 1979. Surf-beach dynamics in time and space - an Australian case study, and elements of a predictive model. Marine Geology 32 (3-4), 231-250.

Chatfield, C., Collins, A., 1980. Introduction to Multivariate Analysis. Chapman and Hall, London and New York.

Clarke, K., Gorley, R., 2006. Primer v6 User Manual/Tutorial. Tech. rep.

Clayton, K., Shamoon, N., 1998. New approach to the relief of Great Britain II. A classification of rocks based on relative resistance to denudation. Geomorphology $25,155-171$.

Costas, S., Alejo, I., Vila-Concejo, A., Nombela, M.A., 2005. Persistence of storm-induced morphology on a modal low-energy beach: a case study from NW-Iberian Peninsula. Marine Geology 224 (1-4), 43-56.

Defeo, O., McLachlan, A., 2005. Patterns, processes and regulatory mechanisms in sandy beach macrofauna: a multi-scale analysis. Marine Ecology Progress Series 295, $1-20$.

Defra, 2002. Final Project Report. Cd-Rom. Halcrow.

Department for Business, Enterprise and Regulatory Reform (BERR), 2008. Atlas of UK Marine Renewable Energy Resources. Technical Report. ABP Marine Environmental Research Ltd. R/3719/8 R.1432.

Dyer, K., Moffat, T.J., 1998. Fluxes of suspended matter in the East Anglian plume southern North Sea. Continental Shelf Research 18, 1311-1331.

Everitt, B., Landau, S., Leese, M., 2001. Cluster Analysis. Arnold, London, UK.

Fairbanks, R.G., 1989. A 17,000-year glacio-eustatic sea level record: Influence of glacial melting rates on the Younger Dryas event and deep-ocean circulation. Nature 342, 637-642.

Flather, R., Smith, J., Richards, J., Bell, C., Blackman, D., 1998. Direct estimates of extreme storm surge elevations from a 40-year numerical model simulation and from observations. The Global Atmosphere and Ocean System 6, 165-176.

Gehrels, W.R., 2010. Late Holocene land- and sea-level changes in the British Isles: implications for future sea-level predictions. Quaternary Science Reviews January.

Gómez-Pujol, L., Orfila, A., Cañellas, B., Alvarez-Ellacuria, A., Méndez, F.J., Medina, R., Tintoré, J., 2007. Morphodynamic classification of sandy beaches in low energetic marine environment. Marine Geology 242 (4), 235-246.

Gourlay, M.R., 1968. Beach and Dune Erosion Tests. Tech. Rep. m935/m936. Delft Hydraulics Lab.

Gower, J.C., 1971. A general coefficient of similarity and some of its properties. Biometrics 27 (4), 857-871.

Hegge, B., Eliot, I., Hsu, J., 1996. Sheltered sandy beaches of Southwestern Australia. Journal of Coastal Research 12 (3), 748.

Jackson, D.W.T., Cooper, J.A.G., 2009. Geological control on beach form: accommodation space and contemporary dynamics. Journal of Coastal Research SI 56, 69-72.

Jackson, N.L., Nordstrom, K.F., Eliot, I., Masselink, G., 2002. 'Low energy' sandy beaches in marine and estuarine environments: a review. Geomorphology 48 (1-3), 147-162.

Jackson, D.W.T., Cooper, J.A.G., del Rio, L., 2005. Geological control of beach morphodynamic state. Marine Geology 216 (4), 297-314.

Jago, C.F., Hardisty, J., 1984. Sedimentology and morphodynamics of a macrotidal beach, Pendine sands, SW Wales. Marine Geology 60 (1-4), 123-154.

Jennings, R., Shulmeister, J., 2002. A field based classification scheme for gravel beaches. Marine Geology 186 (3-4), 211-228.

Jennings, S., Orford, J., Canti, M., Devoy, R., Straker, V., 1998. The role of relative sea level rise and changing sediment supply on Holocene gravel barrier development: the example of Porlock, Somerset, UK. Holocene 8, 165-181.

Jiménez, J.A., Guillén, J., Falqués, A., Marine, Geology, 2008. Comment on the article "morphodynamic classification of sandy beaches in low energetic marine environment" by Gómez-pujol, L., Orfila, A., Cañellas, B., Alvarez-Ellacuria, A., Méndez, F.J., Medina, R. and Tintoré, J. Marine Geology, 242, pp. 235-246, 2007. Marine Geology 255 (1-2), 96-101.

King, C., Williams, W., 1949. The formation and movement of sand bars by wave action. Geographical Journal 113, 70-85.

Kruskal, J.B., 1964. Multidimensional scaling by optimizing goodness of fit to a nonmetric hypothesis. Psychometrika 29, 1-27.

Levoy, F., Anthony, E.J., Monfort, O., Larsonneur, C., 2000. The morphodynamics of megatidal beaches in Normandy, France. Marine Geology 171 (1-4), 39-59.

Lippmann, T.C., Holman, R.A., 1990. The spatial and temproal varability of sand bar morphology. Journal of Geophysical Research 95 (C7), 11575-11590 85.

Martín-Grandes, I., S. D. J., C. A. J., Reeve, D.E., 2009. Novel methodology for one line model calibration using impoundment on mixed beaches. Coastal Dynamics.

Masselink, G., 1993. Simulating the effects of tides on beach morphodynamics. Journal of Coastal Research SI 15, 180-197.

Masselink, G., Anthony, E.J., 2001. Location and Height of Intertidal Bars on Macrotidal Ridge and Runnel Beaches.

Masselink, G., Pattiaratchi, C., 2000. Tidal asymmetry in sediment resuspension on a macrotidal beach in Northwestern Australia. Marine Geology 163 (1-4), 257-274.

Masselink, G., Short, A.D., 1993. The effect of tide range on beach morphodynamics and morphology: a conceptual beach model. Journal of Coastal Research 9 (3), 785-800.

Masselink, G., Turner, I.L., 1999. Handbook of beach and shoreface morphodynamics. Ch The Effect of Tides on Beach Morphodynamics. Wiley, Chichester, pp. 204-229. 
Masselink, G., Kroon, A., Davidson-Arnott, R.G.D., 2006. Morphodynamics of intertidal bars in wave-dominated coastal settings - a review. Geomorphology 73 (1-2), 33-49 37.

May, V., Hansom, J., 2003. Coastal Geomorphology of Great Britain. No. 28 in Geological Conservation Review Series. Joint Nature Conservation Committee, Peterborough.

Middleton, G.V., 2000. Data Analysis in the Earth Sciences Using MATLAB. Prentice Hall, New Jersey.

Orford, J.D., Forbes, D.L., Jennings, S.C., 2002. Organisational controls, typologies and time scales of paraglacial gravel-dominated coastal systems. Geomorphology 48 (1-3), 51-85.

Ortega-Sánchez, M., Fachin, S., Sancho, F., Losada, M.A., 2008. Relation between beachface morphology and wave climate at Trafalgar beach (Aádiz, Spain). Geomorphology 99 (1-4), 171-185.

Parker, W., 1975. Nearshore sediment dynamics and sedimentation. Ch Sediment Mobility and Erosion on a Multi-Barred Foreshore (Southwest Lancashire, UK). Wiley, London, pp. 151-179.

Plater, A., Stupples, P., Roberts, H., 2009. Evidence of episodic coastal change during the Late Holocene: the Dungeness barrier complex, SE England. Geomorphology 104 (1-2), 47-58.

Pontee, N.I., Pye, K., Blott, S.J., 2004. Morphodynamic behaviour and sedimentary variation of mixed sand and gravel beaches, Suffolk, UK. Journal of Coastal Research 20 (1), 256-276.

Ramsay, P.M., Kent, M., Reid, C.L., Duckworth, J.C., 2006. Taxonomic, morphological and structural surrogates for the rapid assessment of vegetation. Journal of Vegetation Science 17 (6), 747-754

Ranasinghe, R., Symonds, G., Black, K., Holman, R.A., 2004. Morphodynamics of intermediate beaches: a video imaging and numerical modelling study. Coastal Engineering 51, 629-655.

Rodil, I.F., Lastra, M., 2004. Environmental factors affecting benthic macrofauna along a gradient of intermediate sandy beaches in Northern Spain. Estuarine, Coastal and Shelf Science 61 (1), 37-44.

Sanderson, P.G., Eliot, I., 1999. Compartmentalisation of beachface sediments along the southwestern coast of Australia. Marine Geology 162 (1), 145-164. doi:10.1016/ S0025-3227(99)00046-8 0025-3227.

Scott, T. M., 2009. Beach morphodynamics and associated hazards in the UK. Ph.D. thesis, University of Plymouth.

Scott, T.M., Russell, P.E., Masselink, G., Wooler, A., 2008. High volume sediment transport and its implications for recreational beach risk. Proceedings 31st International Conference on Coastal Engineering. ASCE, Hamburg, Germany, pp. 4250-4262.

Scott, T.M., Russell, P.E., Masselink, G., Wooler, A., 2009. Rip current variability and hazard along a macro-tidal coast. Journal of Coastal Research SI 56, 895-899.

Sedrati, M., Anthony, E.J., 2007. Storm-generated morphological change and longshore sand transport in the intertidal zone of a multi-barred macrotidal beach. Marine Geology 244 (1-4), 209-229 48.

Sénéchal, N., Gouriou, T., Castelle, B., Parisot, J.P., Capo, S., Bujan, S., Howa, H., 2009. Morphodynamic response of a meso- to macro-tidal intermediate beach based on a long-term data set. Geomorphology 107 (3-4), 263-274.

Shaw, J., 1985. Beach morphodynamics of an Atlantic coast embayment: Runkerry Strand, County Antrim. Irish Geography 18 (1), 51-58.

Shepard, R.N., 1962. The analysis of proximities: multidimensional scaling with an unknown distance function. Psychometrika 27, 125-140.
Short, A.D., 1978. Wave power and beach-stages. a global model. Proceedings of the 16th International Conference on Coastal Engineering. ASCE, pp. 1145-1162.

Short, A.D., 1979a. Wave power and beach stages - a global model. Proceedings of the 16th International Conference on Coastal Engineering. Hamburg, pp. 1145-1162.

Short, A.D., 1979b. Three dimensional beach stage model. Journal of Geophysical Research 87, 553-571.

Short, A.D., 1984. Temporal change in beach type resulting from a change in grain size Search 15 (7-8), 228-230.

Short, A.D., 1991. Macro-meso tidal beach morphodynamics - an overview. Journal of Coastal Research 7 (2), 417-436.

Short, A.D., 1992. Beach systems of the central Netherlands coast: processes, morphology and structural impacts in a storm driven multi-bar system. Marine Geology 107 (1-2), 103-132.

Short, A.D., 1993. Beaches of the New South Wales Coast. Australian Beach Safety and Management Project. Sydney University Press, Sydney, Australia.

Short, A.D.E., 1999. Handbook of Beach and Shoreface Morphodynamics. Wiley, New York. 392 pp.

Short, A.D., 2006. Australian beach systems - nature and distribution. Journal of Coastal Research 22 (1), 11-27.

Short, A.D., 2010. Role of geological inheritance in Australian beach morphodynamics. Coastal Engineering 57, 92-97.

Short, A.D., Aagaard, T., 1993. Single and multi-bar beach change models. Journal of Coastal Research SI 15, 141-157.

Short, A.D., Hogan, C., 1994. Rip currents and beach hazards: their impacts on public safety and implications for coastal management. Journal of Coastal Research SI 12 197-209.

Short, A. D. and Jackson, D. W. T., in press, Beach morphodynamics. In Sherman, D. J. (Ed), Coastal geomorphology. Treatise in Geomorphology Series, Elsevier.

Short, A.D., Masselink, G., 1999. Handbook of beach and shoreface morphodynamics. Embayed and Structurally Controlled Beaches. Wiley, pp. 230-249.

Short, A.D., Woodroffe, C., 2009. The Coast of Australia. Cambridge University Press. 302 pp.

Steers, J.A., 1946. The Coastline of England and Wales. Cambridge University Press, Cambridge. 644 pp.

Travers, A., 2007. Low-energy beach morphology with respect to physical setting: a case study from Cockburn Sound, Southwestern Australia. Journal of Coastal Research 23 (2), 429-444.

Turner, I.L., 1993. Water table outcropping on macro-tidal beaches: a simulation model. Marine Geology 115 (3-4), 227-238.

Turner, I.L., 1995. Simulating the influence of groundwater seepage on sediment transported by the sweep of the swash zone across macro-tidal beaches. Marine Geology 125 (1-2), 153-174.

van Houwelingen, S., Masselink, G., Bullard, J., 2006. Characteristics and dynamics of multiple intertidal bars, North Lincolnshire, England. Earth Surface Processes and Landforms 31 (4), 428-443.

Wright, L.D., Short, A.D., 1984. Morphodynamic variability of surf zones and beaches: a synthesis. Marine Geology 56 (1-4), 93-118.

Wright, L.D., Chappell, J., Thom, B.G., Bradshaw, M.P., Cowell, P., 1979. Morphodynamics of reflective and dissipative beach and inshore systems: Southeastern Australia. Marine Geology 32 (1-2), 105-140.

Wright, L.D., Short, A.D., Boon Iii, J.D., Hayden, B., Kimball, S., List, J.H., 1987. The morphodynamic effects of incident wave groupiness and tide range on an energetic beach. Marine Geology 74 (1-2), 1-20. 